\title{
Ascorbate is a multifunctional micronutrient whose synthesis is lacking in primates
}

\author{
Junichi Fujii* \\ Department of Biochemistry and Molecular Biology, Graduate School of Medical Science, Yamagata University, Yamagata 990-9585, Japan
}

(Received 6 November, 2020; Accepted 7 December, 2020; Published online 25 March, 2021)

\begin{abstract}
Ascorbate (vitamin C) is an essential micronutrient in primates, and exhibits multiple physiological functions. In addition to antioxidative action, ascorbate provides reducing power to $\alpha$-ketoglutarate-dependent non-heme iron dioxygenases, such as prolyl hydroxylases. Demethylation of histones and DNA with the aid of ascorbate results in the reactivation of epigenetically silenced genes. Ascorbate and its oxidized form, dehydroascorbate, have attracted interest in terms of their roles in cancer therapy. The last step in the biosynthesis of ascorbate is catalyzed by L-gulono- $\gamma$-lactone oxidase whose gene Gulo is commonly mutated in all animals that do not synthesize ascorbate. One common explanation for this deficiency is based on the increased availability of ascorbate from foods. In fact, pathways for ascorbate synthesis and the detoxification of xenobiotics by glucuronate conjugation share the metabolic processes up to UDP-glucuronate, which prompts another hypothesis, namely, that ascorbate-incompetent animals might have developed stronger detoxification systems in return for their lack of ability to produce ascorbate, which would allow them to cope with their situation. Here, we overview recent advances in ascorbate research and propose that an enhanced glucuronate conjugation reaction may have applied positive selection pressure on ascorbate-incompetent animals, thus allowing them to dominate the animal kingdom.
\end{abstract}

Key Words: ascorbate, vitamin C, glucuronate conjugation, detoxification

$\mathrm{V}$ itamins are nutrients that are, in the original meaning, essential micronutrients that cannot be synthesized by an organism. About a century ago, Szent-Györgyi ${ }^{(1)}$ discovered that high levels of ascorbate (Asc) are stored in the adrenal gland, and this stimulated research interest in this compound. The inability to synthesize a vitamin is generally due to a lack genes responsible for their syntheses that developed during the evolutional process, however, applying this scenario to Asc is not quite correct. In fact, most organisms, including mammals, are able to synthesize Asc from glucose as the primary carbohydrate. On the contrary, the ancestors of primates and some other species once had the ability to synthesize Asc but have lost this ability during their evolution. ${ }^{(2,3)}$

Humans need to ingest massive amounts of Asc compared to other vitamins for health maintenance; the recommended daily requirement for Asc is $75-110 \mathrm{mg} /$ day for adult humans. ${ }^{(4)}$ A high excretion rate from the body through the kidneys; a half-life being approximately one day, is the main contributor to this massive requirement. Regarding physiological roles, antioxidation and electron donation in the synthesis of biological compounds, such as collagen and catecholamines, are well established functions of Asc. ${ }^{(5,6)}$ Recent advances in this area have revealed that the contribution of Asc can be extended to the oxygen-dependent regulation of gene expression via the hypoxia-inducible factor (HIF)-1 $\alpha^{(7)}$ and the epigenetic regulation of genes. ${ }^{(8,9)}$ In the meantime, since the proposal by Linus Pauling on the use of Asc for cancer therapy, the benefits of high doses of Asc in the treatment of cancer has been a subject of considerable debate. $^{(10)}$ Accumulating evidence, based on basic and clinical studies, are now confirming that Asc can, in fact, be useful in cancer prevention and treatment. ${ }^{(11)}$

Phylogenetically, vertebrates higher than fish possess the Gulo encoding L-gulono- $\gamma$-lactone oxidase (Gulo), which catalyzes the last step in Asc synthesis. ${ }^{(12)}$ A mutation in Gulo occurred about $63,000,000$ years ago, which makes primates unable to synthesize Asc. ${ }^{(13)}$ In fact, mutations have been observed in Gulo in all incompetent animal species, which include guinea pigs, bats, passeriformes birds, and teleost fish. ${ }^{(3,14,15)}$ These animals can ingest sufficient amounts of Asc from foods in ordinary life, so that Asc production may not be essential for their health. However, the question remains about what has allowed these incompetent animals in which Gulo was mutated to dominate during their evolution.

In this review article, we briefly overview the multiple functions of Asc with specific emphasis on recent advances in our understanding of the beneficial roles of Asc in our health and propose a mechanism regarding selection pressure that may have allowed animals that are unable to produce Asc continue to dominate.

\section{Anti-oxidative and Redox Reaction of Asc}

The chemistry of ascrobic acid has been extensively overviewed, ${ }^{(16,17)}$ and this is not the subject of this article. Accordingly, only minimal information concerning the structure and the chemical nature of Asc that are required for our understanding of its physiologica funcitons, are provided here. While ascorbic acid is present mainly in three states: the fully oxidized form (dehydroascorbate; DHA), the ascorbyl radical and the fully reduced monoanion form, Asc is the dominant form at physiological $\mathrm{pH}$ and is a potent reducing agent (Fig. 1). Asc readily undergoes a one-electron oxidation to form an ascorbyl radical and then DHA. In other words, due to its high electron-donating ability, Asc is involved in a variety of reactions that require reducing equivalents in both enzymatic and non-enzymatic reactions. The resulting oxidized form, DHA is either recycled by several processes that are described below or is converted into 2,3-diketo-L-gulonic acid, which is then further metabolized via L-xylose, L-threonic acid plus oxalic acid, or L-xylonic acid and L-lyxonic acid. ${ }^{(6)}$ Asc concentrations in the plasma/extracellular fluid and cells/tissues are 0.04-0.08 $\mathrm{mM}$ and $0.3-10 \mathrm{mM}$, respectively. ${ }^{(10,18)}$ A short half-life of

*To whom correspondence should be addressed.

E-mail: jfujii@med.id.yamagata-u.ac.jp

He received "The SFRR Japan Prize" in 2020 in recognition of his outstanding work. 

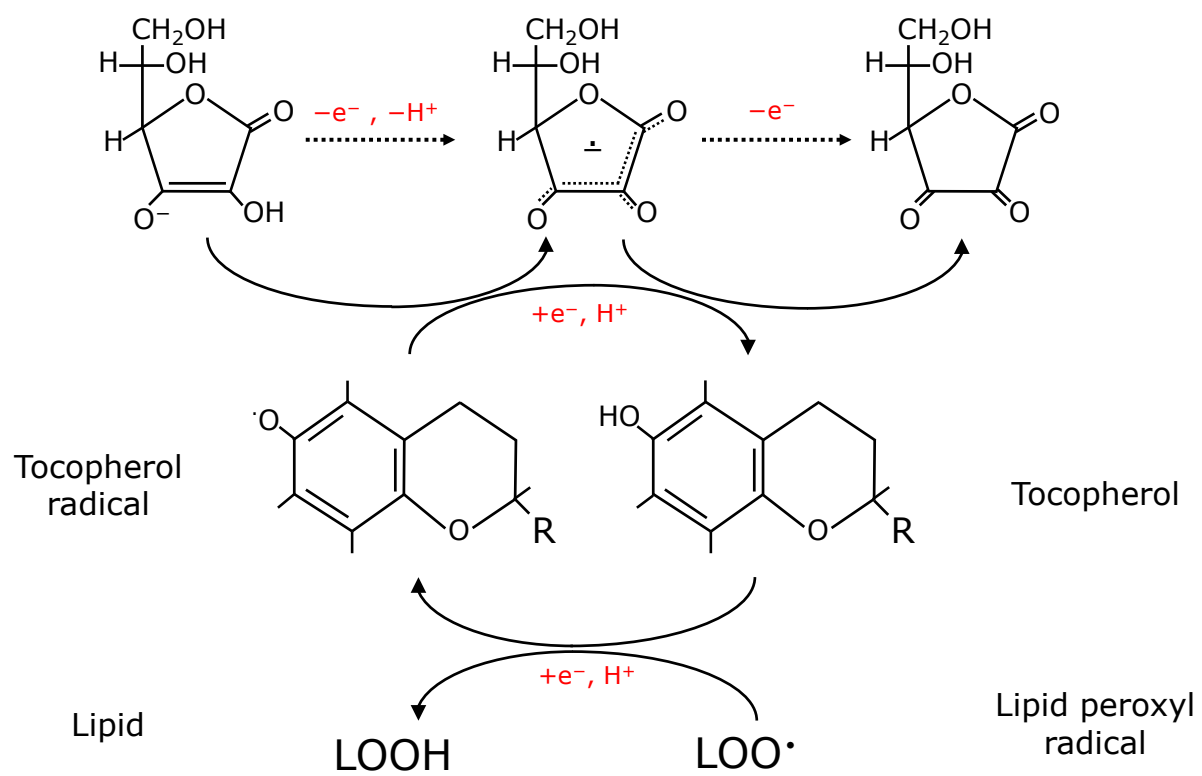

Fig. 1. Interconversion of Asc, ascorbyl radical and DHA and their roles in the vitamin E-mediated elimination of lipid radical. Three major forms of ascorbic acid and their redox-mediated interconversion are depicted on the top. Vitamin E (tocopherol) donates electron to lipid hydroxyl radical (LOO') and is converted to tocopherol radical. Asc may donate an electron to a tocopherol radical for recycling and is converted to an ascorbyl radical, which is then oxidized to DHA. Asc collectively can protect lipids from oxidation reactions as well. Schemes show conceptual reactions and are not stoichiometric. $\mathrm{R}$; alkyl side chain.

approximately one day in mammals is mainly due to the high excretion rate and insufficient reuptake in the kidney. Due to less abundance of DHA and high level of reductive recycling, the issue of how much of the DHA-derived metabolites are subsequently metabolized remain ambiguous.

Anti-oxidation is a major function of Asc and has been extensively reviewed. ${ }^{(17,19,20)}$ Asc is a safe and relatively cheap antioxidative compound and is generally used as a food additive in commercial food products. The antioxidative capacity of Asc is largely attributed to its ability to donate an electron and be converted into a radical species, typically a hydroxyl radical, a vitamin E ( $\alpha$-tocopherol) radical and a thyl radical. ${ }^{(19)}$ While Asc is a highly water-soluble molecule and can function to suppress hydrophilic radical species, vitamin $\mathrm{E}$ provides protection against lipid peroxidation by donating electrons to lipid peroxyl radicals (LOO'). Experimental data indicate that Asc is able to recycle vitamin $\mathrm{E}$ radicals back to vitamin $\mathrm{E}$, and hence, also functions to protect lipids against peroxidation. Because of this, both Asc and vitamin $\mathrm{E}$ are often discussed together as nutritional antioxidants. ${ }^{(16,21)}$ Because lipid peroxidation products trigger ferroptosis, a newly identified type of iron-dependent non-apoptotic cell death, ${ }^{(22,23)}$ Asc may also be involved in the suppression of ferroptosis via the reductive recycling of vitamin $\mathrm{E}$, a potent anti-ferroptotic compound. In the meantime, Asc is not a very effective scavenger of superoxide, a primary oxygen radical, according to the rate constant for this reaction $\left(2.7 \times 10^{5} \mathrm{M}^{-1} \mathrm{~s}^{-1}\right)^{(24)}$ which is about half that for the spontaneous dismutation of superoxides. However, because of the abundance of Asc in tissues, this allows the reaction between superoxide and Asc to proceed sufficiently rapidly to suppress superoxide to permissible levels in vivo. ${ }^{(25)}$ Because superoxide is the oxygen radical that is first produced under a variety of reactions with oxygen consumption, its elimination would be of importance for suppressing subsequent radical chain reactions and hence provide relief from oxidative stress.
Asc is also closely associated with iron homeostasis and function. In cooperation with ferrireductase including duodenal cytochrome $\mathrm{B}$, ferric iron $\left(\mathrm{Fe}^{3+}\right)$ is reduced to ferrous iron $\left(\mathrm{Fe}^{2+}\right)$ by Asc and is then taken up by apical membranes in the intestinal lumen via the divalent metal ion transporter DMT1.(26) Hence, an Asc insufficiency decreases the intestinal absorption of iron and causes iron-deficient anemia. ${ }^{(27)}$ Asc stimulates the synthesis of the iron-storage protein ferritin, inhibits its lysosomal degradation, and decreases the efflux of iron from cells. ${ }^{(28)}$ Moreover, Asc-dependent enzymatic reactions are dependent on iron in most cases and copper occasionally. ${ }^{(5)}$ It is noteworthy, however, that Asc in pharmacologic concentrations is converted to excessive levels of ascorbyl radicals and is simultaneously involved in production of hydrogen peroxide in a free-iron dependent manner in extracellular fluid. ${ }^{(29)}$ Thus, Asc may also act as a pro-oxidant and exert cytotoxicity, depending on the redox environment, which appears to be an underlying mechanism for the anti-cancer action of Asc. ${ }^{(30)}$

\section{Outline of Asc Biosynthesis}

Asc is synthesized dominantly in the liver from glucose as a primary carbohydrate via several processes, ${ }^{(31,32)}$ and the pathway cross-talks with other glucose metabolic pathways (Fig. 2). Accordingly nutritional conditions can have a significant effect on Asc synthesis and can have an influence on the Asc levels in the body. Upon feeding, cells take up glucose from the blood via a glucose transporter (GLUT) and phosphorylate glucose to glucose-6-phosphate (glucose-6-P) via the action of hexokinase/ glucokinase. Glucose-6-P is then either degraded by glycolysis, converted to other carbohydrates via the pentose phosphate pathway, or isomerized to glucose-1-phosphate (glucose-1-P) by phosphoglucomutase. Glucose-1-P uridylyltransferase, also referred to as UDP-glucose pyrophosphorylase, then converts glucose-1-P into UDP-glucose which serves as the communal 


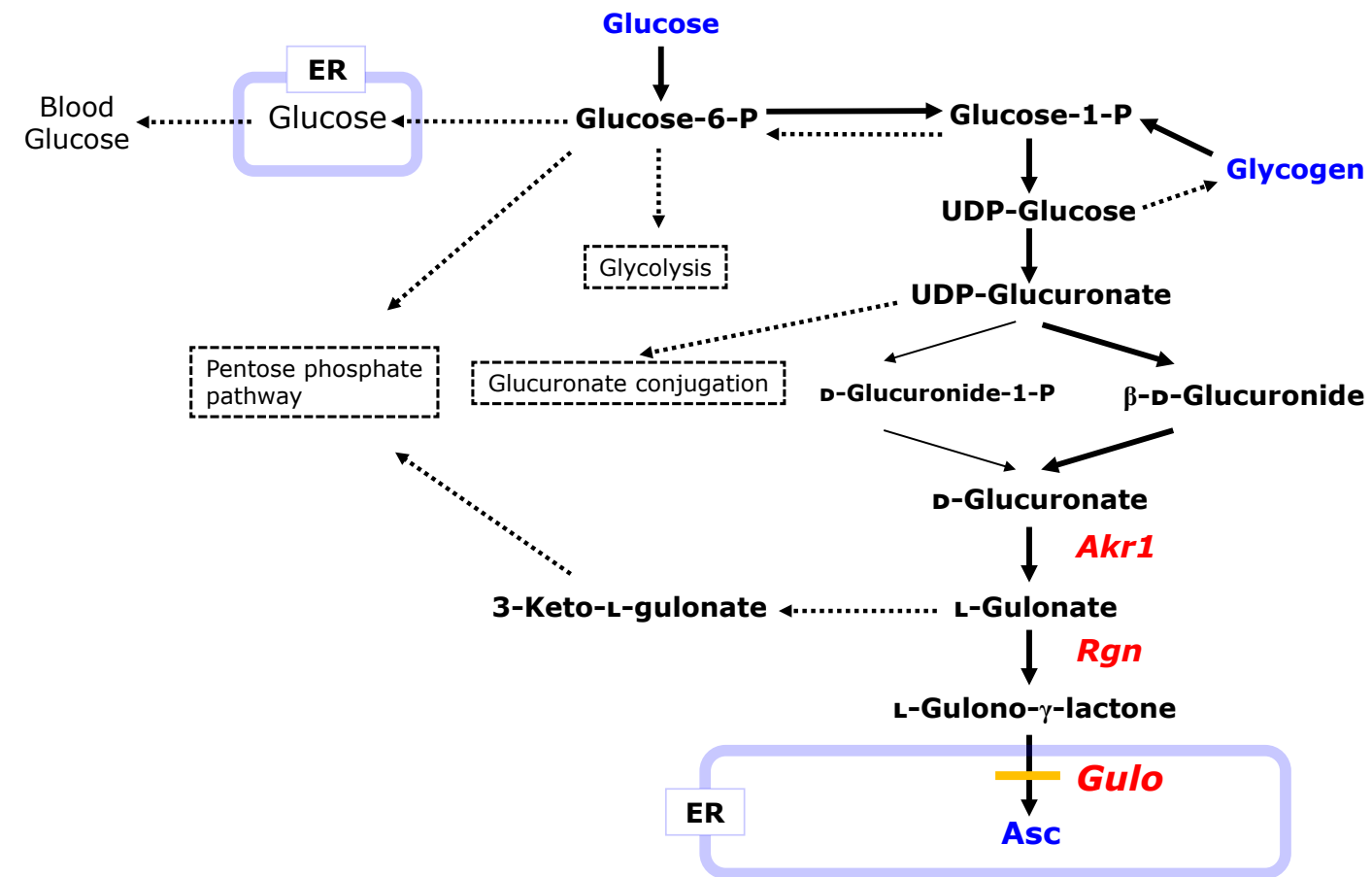

Fig. 2. Pathways for Asc synthesis and other related carbohydrate metabolism pathways from glucose. Solid lines indicate carbon flow to Asc synthesis. Dotted lines indicate flows that simultaneously or occasionally procced depending on the physiological conditions of the animals. Gulo in the ER is absent in incompetent animals of the Asc synthesis.

precursor for glycogen synthesis and Asc synthesis. ${ }^{(32)}$

UDP-glucose is oxidized to UDP-glucuronate, which then flows to the Asc synthesis or is used for glucuronate conjugation for purposes of detoxification. ${ }^{(33)}$ In the biosynthesis of Asc, D-glucuronate is produced from UDP-glucuronate via either D-glucuronide-1-phosphate (D-glucuronide-1-P) or D- $\beta$ glucuronide. The resulting D-glucuronate is reduced by members of the aldo-keto reductase family (Akr)-1 ${ }^{(34)}$ to L-gulonate, which is then converted to either L-gulono- $\gamma$-lactone for Asc synthesis or 3-keto-L-gulonate leading to the pentose phosphate pathway. The conversion of L-gulonate to L-gulono- $\gamma$-lactone is catalyzed by gluconolactonase (Rgn). L-Gulono- $\gamma$-lactone is transported into the endoplasmic reticulum (ER) lumen and eventually oxidized to Asc by the catalytic action of Gulo. ${ }^{(32)}$

Glycogen is an energy storage form of carbohydrate, and glycogenolysis, upon stimulation with a hyperglycemic hormone such as glucagon, provides glucose to the body via the blood. In this response, glucose-1-P is released by glycogen phosphorylase, isomerized to glucose-6-P by phosphoglucomutase, and finally dephosphorylated to glucose by glucose 6-phosphatase (G6Pase) in the lumen of the ER (Fig. 3). Glucagon, the levels of which are increased in blood under hypoglycemic conditions and the principle hormone for maintaining blood glucose levels, stimulates glycogenolysis but does not activate Asc synthesis. ${ }^{(35)}$ There is a large body of evidence to support the conclusion that Asc is also synthesized upon activation of glycogenolysis in competent animals such as rodents. ${ }^{(2,32)}$ For example, Asc synthesis is reportedly stimulated under glutathione depletion by either inhibiting glutathione synthesis $^{(36)}$ or activating glutathione conjugation in rodents, ${ }^{(35,37)}$ although blood glucose levels remain unchanged by these treatments. ${ }^{(37,38)}$ For this purpose, glucose-1-P is converted into UDP-glucose only for Asc synthesis. Thus, there appears to be mechanisms that preferentially force glycogen-derived glucose-1-P to flow toward Asc production. These phenomena imply the existence of a line of communication between the glutathione system and the Asc system, but the molecular basis for this crosstalk is not clearly understood. ${ }^{(32)}$ We will revisit this issue in a later section and discuss it from evolutional aspect of Asc synthesis.

It is also of note that oxygen consumption by Gulo produces hydrogen peroxide as a byproduct, which may be reduced to water during the oxidative folding of secretory proteins. Although an excessive production of hydrogen peroxide may trigger oxidative stress and eventually ER stress partly due to stimulating the misfolding of proteins, ${ }^{(39)}$ a causal connection between the hydrogen peroxide released by the Gulo reaction and ER stress is obscure. Upon the dysfunction of Gulo in Ascincompetent animals, upstream intermediary compounds of Lgulono- $\gamma$-lactone tend to flow toward other metabolic pathways and may be metabolized in different ways.

\section{Asc Transport and the Reductive Recycling of DHA}

The resulting Asc is released into the blood and delivered to organs. Asc is taken up by cells via a member of the $\mathrm{Na}^{+}-$ dependent vitamin $\mathrm{C}$ transporter (SVCT) family that is driven by the $\mathrm{Na}^{+}$gradient (Fig. 4). ${ }^{(40,41)}$ On the other hand, DHA is taken up via facilitative glucose transporters ${ }^{(42)}$ that include GLUT1, GLUT3, and GLUT4 ${ }^{(43,44)}$ as well as others. ${ }^{(45)}$ Given presence of abundant levels of $\mathrm{Na}^{+}$in the extracellular fluid and that Asc is the major form in the blood and extracellular milieu, ${ }^{(46)}$ SVCTs dominantly contribute to the uptake of Asc by cells and generate large concentration gradients. ${ }^{(47)}$ Consequently, Asc levels are maintained at high levels in cells, 0.5 to $10 \mathrm{mM}$ compared to 50 to $80 \mu \mathrm{M}$ in blood plasma. ${ }^{(48)}$ The distribution of the two isoforms of the Asc transporters is discrete: SVCT1 (also referred to as solute carrier family 23 member 1; Slc23a1) in the intestine, kidney and liver cells, whereas it is SVCT2 (Slc23a2) in the brain, eye and other organs. SVCT1 which is expressed in the intestine and kidney, is involved in the absorption of Asc from nutritional sources and reabsorption from filtrate, 


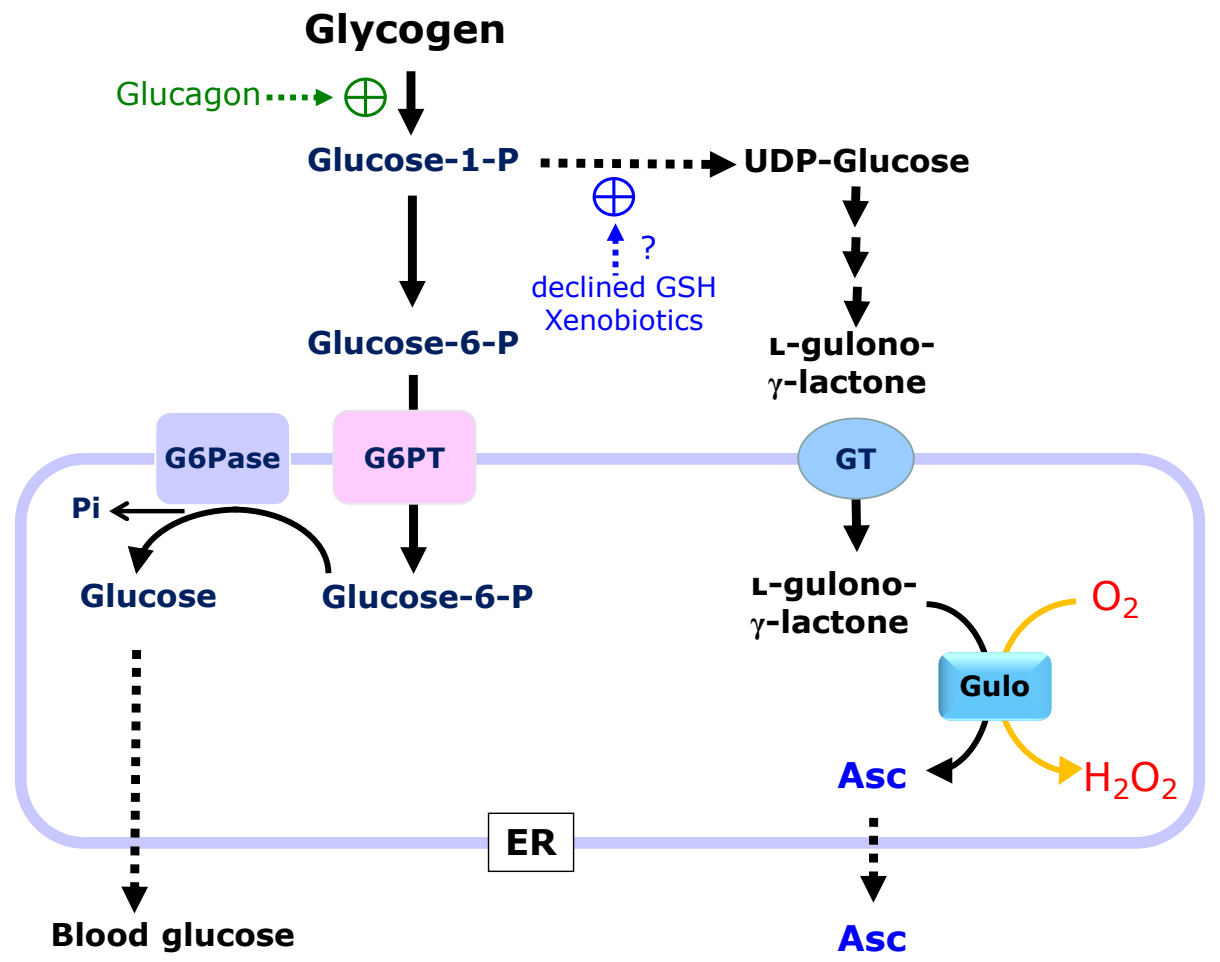

Fig. 3. Roles of ER in the production of glucose via glucose 6-P and Asc via UDP-glucose from glycogen in rodents. Glucose 1-P from glycogen is the common precursor for plasma glucose and Asc. Glucagon stimulates glycogenolysis but is not involved in UDP-glucose formation. In the meantime, xenobiotics and glutathione consumption stimulate the production of UDP-glucose and the consequent Asc synthesis, but not blood glucose. Dephosphorylation of glucose 6-P by glucose 6-phosphatase (G6Pase) releases glucose in the ER. Gulo oxidizes L-gulono- $\gamma$-lactone to Asc by means of the oxidation of molecular oxygen, leading to the production of hydrogen peroxide.

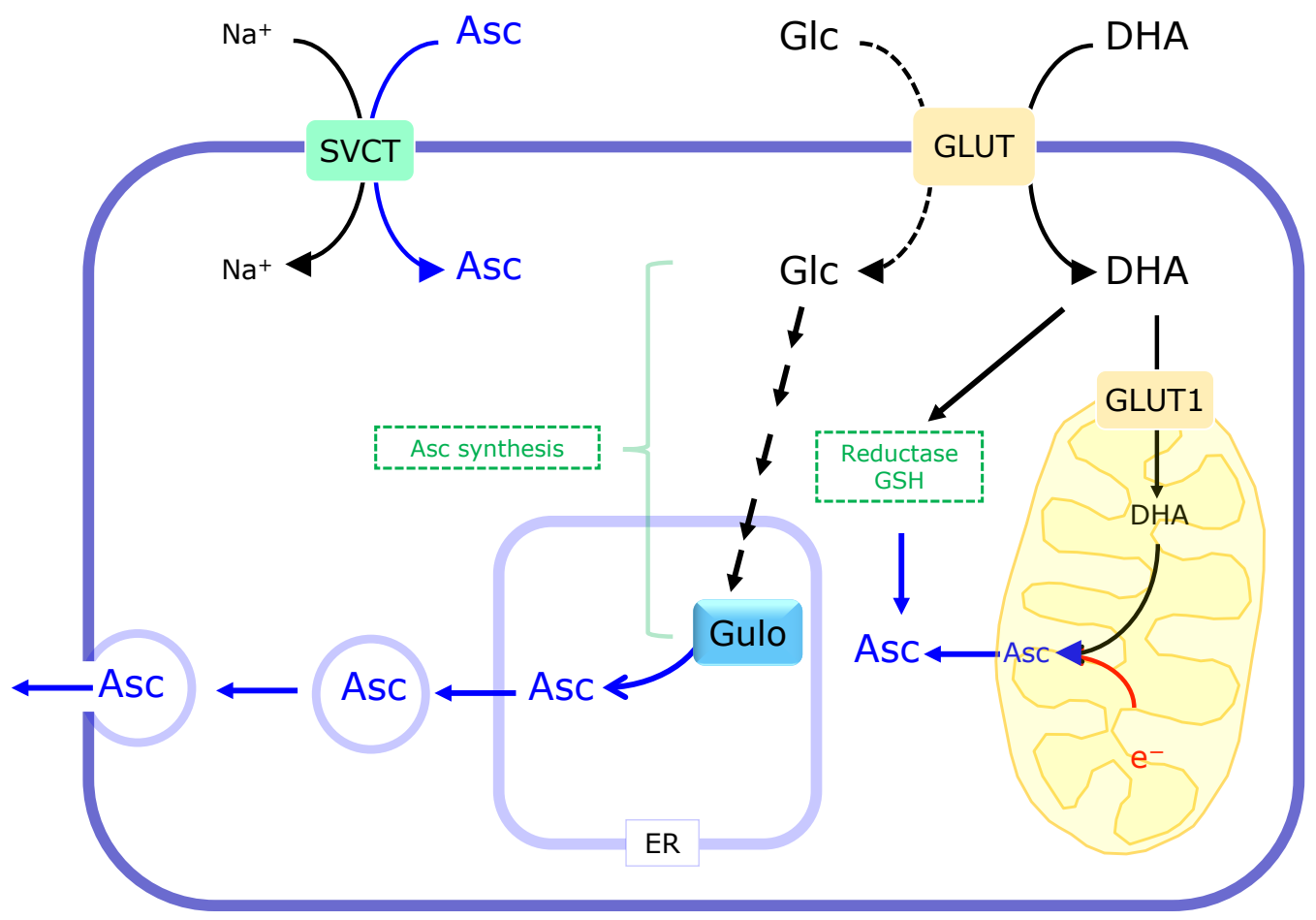

Fig. 4. Transport system for Asc and DHA and the reductive recycling of DHA. Asc is transported via the SVCT which is driven by a Na+ electrochemical gradient. Some types of GLUT are responsible for DHA uptake as well as glucose (GIc) uptake. DHA is reduced to Asc by either enzymatic reactions or an electron donation from glutathione. DHA is partly transported into mitochondria via GLUT and reduced to Asc by electrons from the respiratory chain. 
respectively. SVCT2 is expressed in the brain and accounts for the uptake of Asc from the cerebrospinal fluid, ${ }^{(49)}$ and Asc has significant roles in neuronal functions, can be therapeutic target of neurodegenerative diseases such as Alzheimer's disease, Parkinson's disease and Huntington's disease. ${ }^{(50)}$

The birth of a mouse with a deficiency in SVCT2 is accompanied by respiratory failure and intraparenchymal brain hemorrhage and dies within a few minute after birth. ${ }^{(45)}$ An SVCT2 deficiency also impairs adrenal chromaffin cell function and decreases the tissue adrenalin and noradrenalin and plasma levels of corticosterone, although these appear to not be the cause for lethality. ${ }^{(51)}$ Regarding cellular organelles, next to the ER, mitochondria are rich in Asc. SVCT2 is reportedly present in the mitochondrial membrane and appears to be responsible for the mitochondrial transport of Asc. ${ }^{(52)}$

Genetic ablation demonstrates the roles of SVCT1 in renal Asc reabsorption and perinatal survival. ${ }^{(53)}$ Although SVCT1 is generally believed to be responsible for the intestinal absorption of Asc, its transport across the intestines is normal in SVCT1-knockout (KO) mice, ${ }^{(53)}$ indicating the presence of an alternative transport mechanism. Functional analyses of the glucose transporters GLUT2 and GLUT5-12 that are expressed in Xenopus oocytes indicate that GLUT2 and GLUT8 are able to take up DHA. ${ }^{(54)}$ Hence, DHA is taken up from intestinal fluids via GLUT2 and GLUT8, and after reduction to Asc, is recruited through the liver. Asc is abundantly present in the central nervous system. SVCT2 is highly expressed and appears to function in the cortex and cerebellum of the fetal rat brain. ${ }^{(55)}$ However, the blood-brain barrier may interfere with the absorption of hydrophilic compounds, including Asc. GLUT1, which is expressed on endothelial cells at the blood-brain barrier, appears to transport DHA into the brain and is responsible for supplying Asc to neurons. ${ }^{(56)}$ Asc has multiple roles in the brain, so please refer to recent review articles ${ }^{(18,50)}$ concerning details regarding the regulation of Asc homeostasis and functions. Because the mouse can synthesize Asc, the ablation of these transporter genes under a genetic background with defected Asc synthesis may cause the production of different phenotypes.

DHA is partly reduced by glutathione, ${ }^{(20)}$ and at a more accelerated rate, by that utilize an electron from glutathione or $\mathrm{NADH} / \mathrm{NADPH}$. NADH-cytochrome b5 reductase is one such enzyme that is responsible for the reduction of DHA, ${ }^{(57,58)}$ but there appears to be more enzymes involved in its reductive recycling. ${ }^{(59,60)}$ For example, protein disulfide isomerase (PDI) catalyzes the reduction of DHA in conjunction with disulfide bond formation in proteins within the ER, which, as viewed from the opposite side, implies that DHA plays a role in oxidative protein folding. ${ }^{(61)}$ DHA is incorporated into mitochondria via GLUT1 which is localized on the inner mitochondrial membrane $^{(62)}$ and is then reduced to Asc by an electron from either glutathione ${ }^{(63)}$ or the electron transport complex III. ${ }^{(64)}$ Upon reduction, Asc may be transported out of mitochondria via SVCT2.

\section{Asc as a Cofactor for Non-heme Iron Dioxygenases}

In addition to antioxidation, another well-recognized action of Asc is to donate electrons for enzymatic processes that require reducing equivalents for the production of a variety of compounds, such as collagen, monoamines, and steroid hormones. ${ }^{(5,65)}$ Asc is a cofactor for $\alpha$-ketoglutarate $(\alpha \mathrm{KG})$ dependent non-heme iron dioxygenases that include prolyl 4-hydroxylase for collagen synthesis and a unique prolyl hydroxylase for HIF-1 $\alpha . .^{(7,66)}$ The prolyl hydroxylases utilize Asc, molecular oxygen and $\alpha \mathrm{KG}$ as co-substrates for proline hydroxylation and result in the formation of DHA, carbon dioxide and succinate (Fig. 5A).

Collagens are the most abundant proteins in the body, constituting $\sim 30 \%$ of the total protein mass in the human body, and the proline residues are highly hydroxylated $(\sim 100$ in each molecule). ${ }^{(67)}$ Asc is a well-established electron donor for the prolyl 4-hydrolase reaction that is required for the maturation of collagen. Scurvy is a disease that is accompanied by aberrant collagen synthesis and is caused by a Asc insufficiency. ${ }^{(68)}$ On the contrary, the excessive production of collagen, notably by myofibroblasts, may cause fibrosis under pathological conditions and result in tissue remodeling. ${ }^{(69)}$ Vertebrates produce three types of collagen prolyl 4-hydroxylase that function in the ER where disulfide bond-mediated oxidative protein folding occurs (Fig. 5B). Prolyl 4-hydroxylases consist of a unique catalytic $\alpha$-subunit, which is responsible for the actual proline hydroxylation, and a common $\beta$-subunit, which is identical to PDI. ${ }^{(66)} \mathrm{PDI}$ alone functions as an independent enzyme that plays roles in the oxidative folding of general secretory proteins in the ER as well as in the restoration of erroneous disulfide bonds. ${ }^{(70)}$ Hence, prolyl 4-hydroxylases may be the self-contained enzyme that participates in the maturation of collagen. The requirement of PDI as a subunit for prolyl 4-hydroxylases may be associated with the lethality in PDI-KO mice due to the inability to synthesize collagen. ${ }^{(71)}$ While Asc supports collagen synthesis by donating an electron for proline hydroxylation, DHA may be involved in the oxidative folding of collagen and other secretory proteins by accepting an electron via PDI. ${ }^{(61)}$ However, because the rate of PDI-medicated reduction of DHA is not very rapid, (72) the extent of the contribution of DHA to oxidative protein folding is obscure.

\section{Animal Models with Defected Asc Synthesis}

About 60 years after the discovery of Asc by Szent-Györgyi, ${ }^{(1)}$ genetic defects in the human gene encoding Gulo were characterized. ${ }^{(13)}$ Among rodents, the guinea pig also carries an evolutionary defect in the Gulo gene ${ }^{(73)}$ and has been utilized as a model animal for Asc function in vivo. ${ }^{(74)}$ A natural mutant the Wistar rat strain, osteogenic disorder Shionogi (ODS), also carries a mutation in Gulo and develops scurvy, ${ }^{(75)}$ despite it being less popular as a pathological model compared to the guinea pig. Since the mouse is the most popular laboratory animal, a huge amount of data on gene function and metabolism has accumulated. Thus, the mouse with a genetic ablation of the specific gene for Asc synthesis would be more advantageous as a pathological model animal.

The Gulo-KO mouse, which exhibits pathological conditions similar to scurvy in humans, was established by the homologous recombination of the gene ${ }^{(76)}$ and has been employed successfully to study the physiological action of Asc. ${ }^{(77)}$ The penultimate reaction in the Asc synthesis, the dehydration of L-gulonate to L-gulono- $\gamma$-lactone, is catalyzed by Rgn. The gene product of Rgn was found to be identical to the senescence marker protein $30 .{ }^{(78)}$ The preceding reaction of Rgn is the NADPH-dependent reduction of D-glucuronic acid to L-gulonate. ${ }^{(79)}$ This process is catalyzed by two closely related enzymes, namely, aldehyde reductase $(\mathrm{Akrla})$ and aldose reductase $(\mathrm{Akrlb})$ in the mouse, which are members of the aldo-keto reductase superfamily. ${ }^{(34,80)}$ The contribution of Akrla and Akrlb in the mouse is $85-90 \%$ and $10-15 \%$, respectively. Even in the presence of $\sim 15 \%$ Asc for the wild-type (WT) mouse, the Akrla-KO mouse starts dying after 20 weeks and does not survive beyond one year, whereas Asc supplementation extends their life-span to a considerable extent. ${ }^{(81)}$ On the other hand, the $A k r 1 b$-KO mouse shows no such phenotypic abnormality. ${ }^{(34)}$ These genetically modified mice have been extensively employed in studies of the roles of Asc from the standpoints of physiology and pathophysiology. ${ }^{(77,82)}$

While the oxidative conversion of L-gulono- $\gamma$-lactone to Asc appears to be the sole reaction catalyzed by Gulo, additional functions may reside in other gene products that are involved in 
A

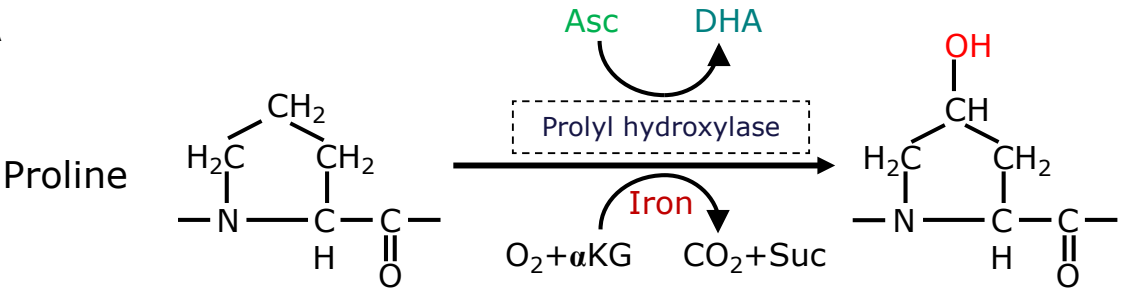

Hydroxyproline

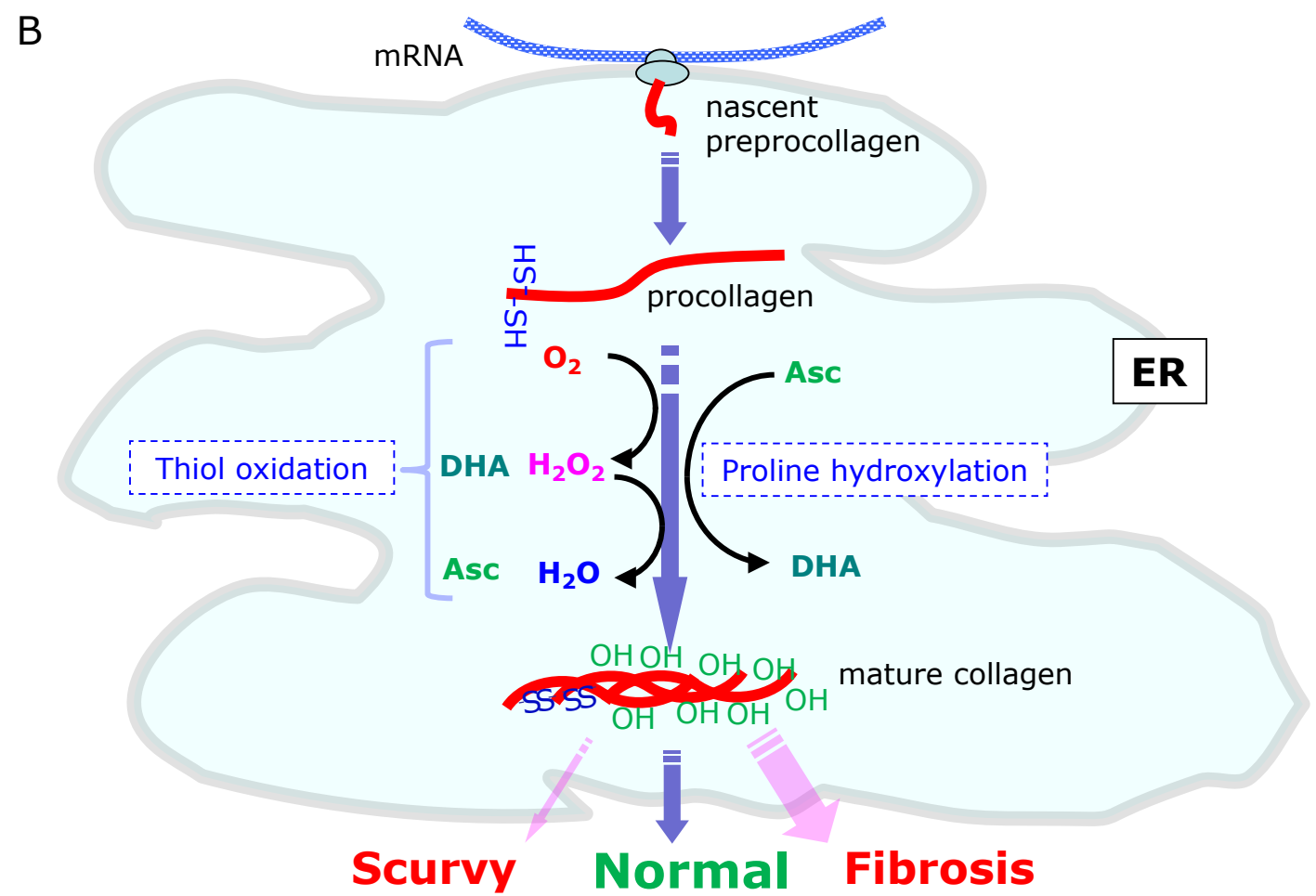

Fig. 5. Proline hydroxylation and the maturation of collagen in the ER. (A) Proly hydroxylase catalyzes the oxidative conversion of proline to hydroxyproline by employing Asc, molecular oxygen and $\alpha$-ketoglutarate $(\alpha \mathrm{KG})$ and results in the production of $\mathrm{DHA}$, carbon dioxide $\left(\mathrm{CO}_{2}\right)$ and succinate (Suc). (B) Oxidative folding and the prolyl hydroxylation of collagen proceed in the ER lumen. Procollagen and other secretory proteins undergo oxidative folding by means of ERO1 and other thiol oxidases. The resulting procollagen is hydroxylated at proline residues by prolyl hydroxylase coupled with Asc oxidation at multiple positions ( 100 proline residues in a molecule) and then secreted out of the cell. DHA may also be involved in thiol oxidation. Both an Asc insufficiency and abundance may cause pathological conditions, such as scurvy and fibrosis, respectively.

the synthesis of Asc. Notably in the case of Akr1a/1b, multiple carbonyl compounds can serve as substrates for these enzymes, ${ }^{(83)}$ and hence, an Akrla-deficiency may result in the development of novel phenotypes beyond those expected from the Asc depletion, as has been observed in some reports. ${ }^{(84,85)}$ Moreover, such a genetic deficiency may also change the upstream metabolic flow and result in the development of phenotypes that are not directly associated with Asc functions. To attribute the corresponding phenotype to an Asc deficiency, a simple but reliable criterion is based on observations of whether ot not Asc supplementation could rescue the animals. EDTA, a chelator of divalent cations is sometimes included in supplemental Asc solutions in order to suppress the spontaneous oxidation of Asc. However, because the inclusion of EDTA may cause deficits in metal absorption by metal chelation, notably iron, in the intestine and cause adverse effect in animals, researchers must take this into account in investigations of Asc-involved biological actions. Considering the sufficient absorption of DHA by intestinal cells via GLUT, $(53,54)$ in our studies, we do not include a metal chelator in the Asc solution but, instead, change the Asc-containing water every 2-3 days to avoid the formation of such artifacts.

The genetically modified mice are particularly advantageous in investigating the physiological consequences of an Asc deficiency. For example, when brain slices of the Rgn-KO mouse are subjected to the hypoxia-reperfusion treatment, Asc effectively suppresses superoxide production as judged by measuring the fluorescence of lucigenin. ${ }^{(86)}$ Asc deprivation causes pulmonary emphysema with decreased collagen synthesis in the Rgn-KO mouse. ${ }^{\left({ }^{87}\right)}$ A double deficiency of Rgn and SOD1, which encodes the superoxide dismutase isoform which is abundantly present in cytosol and to a more limiter extent in mitochondria, shows premature death and aberrant lipid metabolism in the absence of Asc supplementation. ${ }^{(88)}$ We recently found that a double deficiency of Akrla and SODI causes inevitable death in the mice within several weeks after the Asc supplementation is ceased. ${ }^{(25)}$ Among the organs examined, oxidative lung injury appears to be the primary cause for the death of the double $\mathrm{KO}$ mouse. These observations strongly support the requisite role of Asc in eliminating superoxide from the body, notably in the lung that is continuously exposed to hyperoxygenic conditions compared to other organs.

To the contrary, an Asc deficiency due to genetic ablation does not always validate the conclusion that Asc is required for enzymatic reactions that have been demonstrated in in vitro 
assays. For example, normal collagen status is observed in the Gul-KO mouse despite the complete absence of Asc and eventual death. ${ }^{(89)}$ In the Rgn-KO mouse, the collagen content is in the skin is not affected, but the levels in the lung are decreased. ${ }^{(90)}$ When the Akrla-KO mouse is subjected to unilateral ureteral obstruction, a pathological model for kidney fibrosis, collagen production is elevated in both Akrla-KO and WT mice, but no evident difference is observed between the two genotypic mice. ${ }^{(81)}$ In other instances, while the levels of noradrenaline and adrenaline are low in adrenal glands of $R g n-\mathrm{KO}$ mice, ${ }^{(91)}$ these levels are not changed in the brain of the Akrla-KO mouse. ${ }^{(92,93)}$ Instead, the levels of adrenaline and noradrenaline are somewhat elevated in the Gulo-KO mice compared to WT mice in a water restraint stress model. ${ }^{(94)}$ These observations imply that Asc is not the sole electron donor for these enzymatic systems, but that other redox-active compounds may compensate for the Asc-insufficient situation. Studies employing Asc-deficient animals, hence, demonstrate that Asc is actually involved in multiple reactions, but, in some instances, redox compounds other than Asc appears to be involved. Thiol compounds, more specifically, glutathione, are promising alternatives to Asc due to their abundance and electron donating ability.

\section{Epigenetic Action of Asc}

Reactive oxygen species (ROS) cause base modifications in DNA and lead to genetic mutations, which may ultimately induce cancer development. 8-Oxo-7,8-dihydroguanine (8-oxoG), is the most frequently modified base, and consequently causes transversion of the GC pair to a TA pair. Hence, the DNA repair glycosylase OGG1 that excises 8-oxoG plays a pivotal role in the suppression of ROS-induced mutation and cancer. ${ }^{(95)}$ While the protective effects of Asc against oxidative damage appear to largely dependent on its antioxidant ability, ${ }^{(96)}$ recent studies have revealed that Asc regulates gene expression via a novel mechanism. The methylation of DNA and histones contributes to the epigenetic regulation of gene expression. DNA methylation at the 5-position of cytosine $(5 \mathrm{mC})$ is catalyzed by DNA methyltransferases (DNMTs). While DNMT3 family enzymes are responsible for de novo methylation and newly establishing the $5 \mathrm{mC}$ in DNA, DNMT1 is involved in the maintenance of $5 \mathrm{mC}$ in the daughter strand during DNA replication. ${ }^{(97)}$ In these cytosine methylation reactions, $S$-adenosylmethionine, which is produced in the process of methionine metabolism, serves as a methyl group donor. Cytosine methylation catalyzed by DNMTs tends to cause chromatin compaction, leading to heterochromatin formation and consequently the silencing of some genes.

In the meantime, histones undergo a variety of modifications, which includes methylation of lysine and arginine residues, acetylation, and ubiquitination, and also affect gene expression epigenetically. ${ }^{(98)}$ Concerning Asc functions, the methylation status in lysine residues is a subject of interest. Histone H3specific methyltransferases were initially found to methylate lysine 9. ${ }^{(99)}$ Thereafter, several specific histone lysine methyltransferases and histone lysine demethylases were identified. ${ }^{(98)}$ While lysine acetylation is largely correlated with the transcriptional activation of genes, the methylation of lysine results in either transcriptional activation or suppression, depending on the position and degree of methylation in the histones.

Because Asc modulates gene expression epigenetically, it has attracted the attention of researchers in the fields of stem cell and cancer research. For example, Asc in fact enhances the generation of induced pluripotent stem cells (iPSCs) from both humans and mice. ${ }^{(100)}$ Asc is a cofactor for $\mathrm{Fe}^{2+}{ }_{-}$and $\alpha \mathrm{KG}$-dependent dioxygenases that involve the demethylation of DNA and histones (Fig. 6). ${ }^{(9,101,102)}$ The ten-eleven translocation (TET) methylcytosine dioxygenase is the enzyme that catalyzes the conversion of $5 \mathrm{mC}$ into 5hydroxymethylcytosine ${ }^{(103)}$ and then 5-carboxylcytosine, which

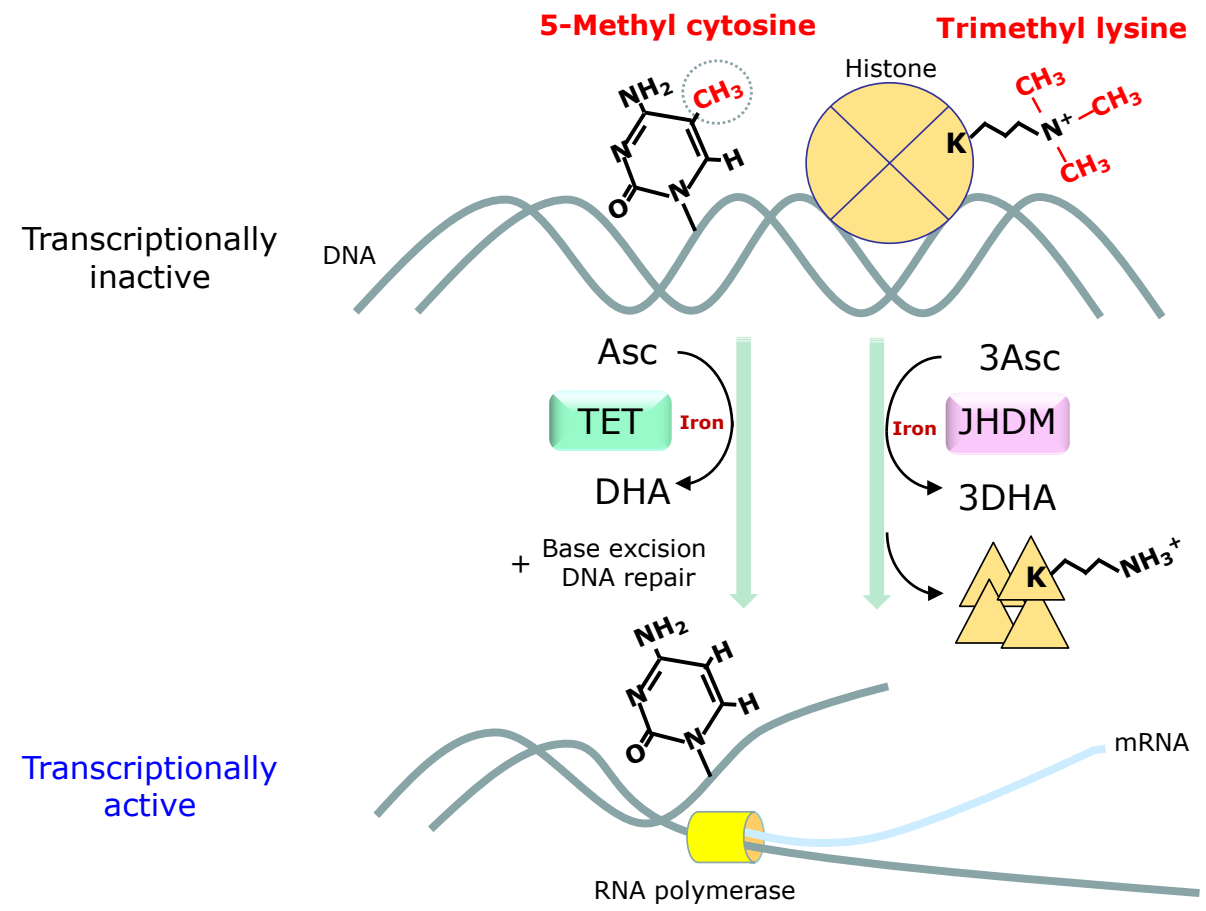

Fig. 6. Epigenetic action of Asc towards gene activation. Electron donation from Asc to TET reaction supports the conversion of 5-methyl cytosine to 5-hydroxyl cytosine and then 5-carboxylcytosine, which is consequently replaced to cytosine by the base excision DNA repair system. Jumonji C (JmjC)-domain-containing histone demethylases (JHDMs) removes methyl groups from lysines in histones. Demethylation of DNA and histones may be able to activate consequent gene expression. Only concept of the reactions are presented schematically. 
is consequently replaced with an unmodified cytosine via a base excision DNA repair system. ${ }^{(104)}$ Asc was first found to induce TET-dependent DNA demethylation in embryonic stem (ES) cells. ${ }^{(105)}$ The TET-catalyzed reaction is accompanied by the conversion of $\mathrm{Fe}^{2+}$ to $\mathrm{Fe}^{3+}$. The electron-donating nature of Asc supports the reductive recycling of $\mathrm{Fe}^{3+}$ to $\mathrm{Fe}^{2+}$. Consequently, genes that have been epigenetically silenced by the methylation of cytosine undergo reactivation by Ascsupported TET reactions. ${ }^{(8)}$

The Jumonji C-domain-containing histone demethylase 1 (JHDM1) is the first identified histone demethylase that specifically demethylates histone $\mathrm{H} 3$ at lysine 36 (H3K36) and is conserved from yeast to humans. ${ }^{(106)}$ JHDM1a/1b has been demonstrated to be the Asc-dependent H3K36 demethylase in mouse embryonic fibroblasts during reprogramming into iPSCs. ${ }^{(107)}$ As the end of this reaction, trimethyl lysine is converted back to lysine in conjunction with the oxidation of three Asc molecules to DHA. Currently, the family contains approximately 20 proteins that catalytically remove methyl groups from methyl lysine with the aid of Asc. ${ }^{(108)}$ Through the epigenetic remodeling of chromatin, an Asc deficiency would be expected to affect a variety of physiological processes, including development, differentiation, and aging and be consequently involved in the development of pathological conditions in animals.

\section{Reactions of Asc in Prevention and Treatment of Cancer}

An early trial with high-dose Asc in the treatment of caner patiens resulted in beneficial action, ${ }^{(109,110)}$ but controversial results were reported in later studies..$^{(11,112)}$ Thus, the use of Asc in the treatment of tumor growth has been a subject of debate since the hypothesis was first announced by Linus Pauling. ${ }^{(11)}$ Asc, in fact, exerts opposing effects, either carcinogenic or tumoricidal, in cancer, which largely depends on the redox status of the microenvironment. Iron can contribute to carcinogenic processes in several ways. ${ }^{(113)} \mathrm{Fe}^{3+}$ bound to ferritin is not toxic in the bound form, however, due to its electron-donating ability, Asc causes the free form of $\mathrm{Fe}^{3+}$ to be converted to $\mathrm{Fe}^{2+}$. $\mathrm{Fe}^{2+}$ supplies electrons for the reductive conversion of hydrogen peroxide to hydroxyl radicals, which are highly reactive, oxidize a variety of molecules including DNA and results in the mutation of genes. Thus, Asc, in conjunction with free iron, may result in elevated ROS levels and exhibit carcinogenicity. By contrast, Asc eliminates ROS as an antioxidant and hence prevents their mutagenic action.

Recent studies have unveiled the anti-tumorigenic action of Asc in which serveral mechanisms are involved. The results of animal experiments indicate that Asc is beneficial in suppressing carcer development; the growth and metastasis of transplanted tumor cells observed in Gulo-KO mice were decreased by supplementation of Asc at physiological concentrations. ${ }^{(114-116)}$ Asc appears to suppress chemical carcinogenesis as well. The administration of $N$-nitrosodiethylamine causes the complete death in Rgn-KO mice within 4 months and therefore provides no information regarding tumorigenesis. ${ }^{(117)}$ Although Akrla-KO mice are also mostly dead within a half-year, a few surviving mice developed extreme hepatocellular carcinomas, and Ascsupplementation markedly suppressed hepatocellular carcinoma development. ${ }^{(118)}$ Because methylation of cytosine in DNA and lysine residues in histones epigenetically suppresses the expression of genes that include tumor suppressor genes, their Asc-mediated demethylation may lead to their reactivation. (9,98) $^{-1}$ Thus, the epigenetic actions of Asc would very likely contribute to the anticarcinogenic action.

Electron donation from Asc to a specific prolyl hydroxylase is responsible for the regulation of HIF- $1 \alpha$, which is a transcription factor and the master regulator of genes whose expression increases oxygen availability. ${ }^{(119)} \mathrm{HIF}-1 \alpha$ levels are increased in many solid tumors and reportedly support their development because the inner mass of solid tumor tends to be hypoxic. The constitutive activation of HIF- $1 \alpha$, hence, induces genes that increase the supply of oxygen and energy production, leading to the survival and proliferation of tumor cells. Asc is utilized for the hydroxylation of specific prolyl residues in HIF-1 $\alpha$, leading to the generation of a binding site for the von HippelLidau (pVHL) tumor suppressor protein, which is made up of a ubiquitin ligase complex (Fig. 7). After polyubiquitination, HIF- $1 \alpha$ undergoes degradation by proteasomes. As a result, Asc in the presence of oxygen may restrict the proliferation and survival of tumor cells. . $^{(7,120)}$

There is an emerging body of evidence to indicate that pharmacologically high-doses of Asc acts as a potential therapeutic agent for some types of cancers. ${ }^{(120-122)}$ Because the plasma Asc level is strictly controlled; $\approx 80 \mu \mathrm{M}^{(123)}$ the oral administration of a high dose of Asc does not reach effective levels. To administer a high dose of Asc for therapeutic purposes, intravenous administration is required; e.g. the intravenous administration of $10 \mathrm{~g}$ of Asc to cancer patients results in $1-5 \mathrm{mM}$ concentrations in the plasma. ${ }^{(124,125)}$ Upon Asc treatment, mitochondrial oxidative metabolism is stimulated and this increases the production of superoxide and hydrogen peroxide, which then disrupts iron metabolism in cancer cells. ${ }^{(126)}$ The resulting labile iron together with hydrogen peroxide sensitizes cancer cells, notably non-small-cell lung cancer and glioblastoma, to pharmacological Asc doses in a redox-active manner. The synergistic action of Asc and iron coordinately trigger lipid peroxidation, which results in ferroptosis in cancer cells. ${ }^{(30,127)}$

In the meantime, colorectal cancer cells bearing mutations in Kras and Braf are selectively killed by the action of a high-dose of DHA. ${ }^{(128)}$ The strategy for killing cancer cells by DHA is different from that for Asc. In this anti-tumor action, glutathione is oxidized in the process of the reduction of DHA to Asc, which results in an elevation in ROS levels. Oxidative DNA damage then stimulates the poly-(ADP-ribose) polymerase-mediated consumption of $\mathrm{NAD}^{+}$, leading to energy depletion and the eventual death of cancer cells. In fact, clinical trials using cancer patients with a fasting-mimicking diet and vitamin $\mathrm{C}$ appears to be promising therapeutics for the treatment of colorectal cancer and possibly other tumors with KRAS mutations. ${ }^{(129)}$ Thus, Asc at physiologic concentrations prevents tumorigenesis, whereas both Asc and DHA at pharmacological doses exert tumoricidal actions.

\section{Evolutional Aspect of Asc Synthesis}

Animals inherently do not possess some genes that are responsible for certain types of metabolism, which leads them to be incapable of synthesizing the corresponding compounds, e.g., essential amino acids and most vitamins. Contrary to these, Asc-incompetent animals had originally possessed functional Gulo but have lost its function due to mutations in the course of evolution. ${ }^{(13)}$ Thus, scenario dealing with Asc synthesis is not comparable to those of essential amino acids or other vitamins. If sufficient Asc is not ingested, our bodies suffer disadvantages due to the inability to produce Asc. Nevertheless, Asc-incompetent animals, including primates, the guinea pig, the bat and passeriformes birds have actually survived. ${ }^{(3,14)}$ In fact, these Asc-incompetent animals have even prospered. The teleost fish, which is the most abundant group in the modern fish family, also cannot synthesize Asc. Different from other Asc-incompetent animals, however, no relic of Gulo has been found in the teleost fish genome by searches of gene data bases. ${ }^{(15)}$ Because the ancestral species can synthesize Asc, it is postulated that Gulo was completely eliminated during the 


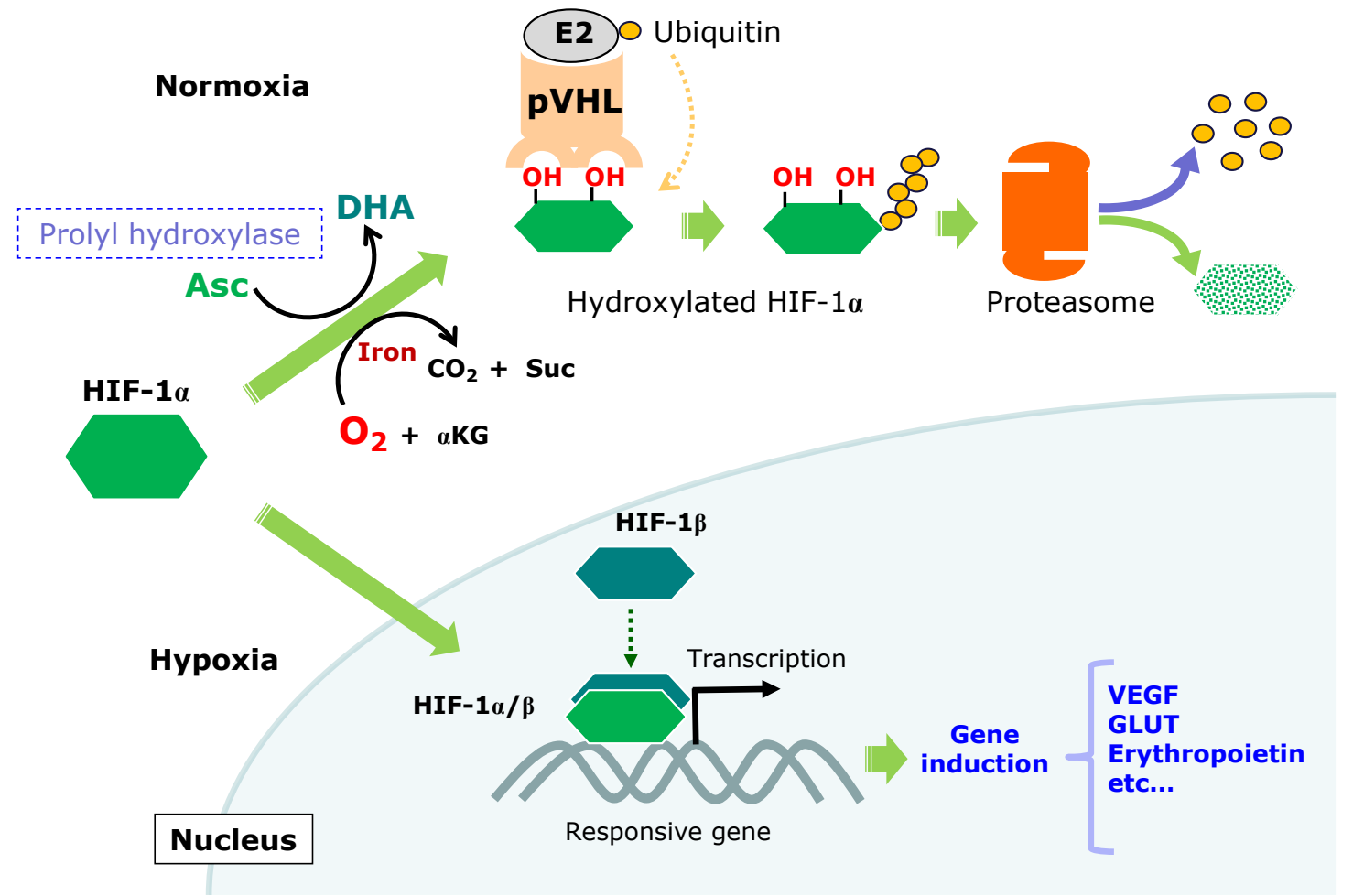

Fig. 7. Roles of Asc in controlling HIF-1 $\alpha$ action. Under normoxic conditions, prolyl hydroxylase catalyzes the hydroxylation of specific proline residues in HIF-1 $\alpha$, which leads to polyubiquitination by the ubiquitin ligase activity of pVHL, followed by degradation via proteasomes. Under hypoxic conditions, the short oxygen supply suppresses proly hydroxylation, which results in the stabilization of HIF-1 $\alpha$. After translocation to the nucleus, HIF-1 $\alpha$ dimerizes with HIF-1 $\beta$, which is constitutively present largely in the nucleus, and together with other transcriptional factors, activates transcription of corresponding genes, such as erythropoietin, vascular epidermal growth factor (VEGF), and GLUT.

course of evolution of the teleost fish. ${ }^{(3)}$ It is of note that Asc incompetence in these animals is caused solely by mutations in Gulo, which can be attributed to independent events during the evolutionary process.

The reason why Asc-incompetent animals are no longer able to synthesize Asc but remain prosperous is not understood and this constitutes an interesting issue from the standpoint of evolution and nutritional biochemistry as well. The most common explanation for the inability to synthesize Asc in primates is as follows; primates can climb trees and therefore gain access to sufficient amounts of Asc-rich foods, notably fruits, and hence do not need to synthesize Asc by themselves. ${ }^{(3)}$ This notion may sound reasonable if the animals do not develop serious damage to their health caused by an Asc insufficiency. In fact, however, Asc exerts a variety of important roles in animal physiology, and an Asc insufficiency causes an unhealthy situation, and in severe cases, fatal conditions such as scurvy. ${ }^{(68)}$ Most genetic mutations, as are found in hereditary diseases, are disadvantageous to the host animals, and hence, tend to be eliminated from the gene pool by death or failure in reproduction. When the mutation is neutral, meaning the mutation does not influence the survival of animals, both the original and mutated genes can be maintained in the gene pool of the animal species because there is no selection pressure on them. However, no active Gulo remains among primates, which suggests that either Gulo itself is disadvantageous or the mutated Gulo is more advantageous for these animals. The question therefore arises as to what mechanism has actually made the incompetent animals lose their ability to synthesize such an important nutrient by assuming the risk of a deficiency disorder?

Gulo is an ER-resident enzyme that converts L-gulono- $\gamma$ lactone to Asc by an oxidation reaction in conjunction with the reduction of molecular oxygen to hydrogen peroxide. Because even a very high dose of Asc is not toxic to animals in the general sense, ${ }^{(123)}$ the presence of excessive levels of Asc does not appear to be harmful to animals. Hydrogen peroxide, a byproduct of the Gulo reaction, is released into the ER lumen, and once excessive levels are reached, it may exert unfavorable events due to its oxidizing power. ${ }^{(130)}$ If Gulo-derived hydrogen peroxide is toxic enough, Asc-competent animals would be more vulnerable to the ER stress compared to the incompetent animals. In fact, the ER is the most hydrogen peroxide-rich organelle and this situation appears to be caused by the action of endoplasmic reticulum oxidoreductin 1 (Ero1), which is involved in oxidative protein folding in the ER and produces large amounts of hydrogen peroxide during the course of the enzymatic reaction. ${ }^{(131,132)}$ Several peroxidases are localized in the ER and utilize hydrogen peroxide for thiol oxidation during oxidative protein folding in the ER. ${ }^{(70)}$ Peroxiredoxin $4(\operatorname{Prdx} 4)$ is one such thiol oxidase that oxidizes thiols in the PDI family or newly synthesized proteins to disulfides. ${ }^{(133)}$ The genetic ablation of Prdx4 alone shows no obvious changes in the mouse, ${ }^{(134)}$ but a mouse with a double deficiency of Prdx4 and Erol develops atypical scurvy due to Asc consumption and insufficient collagen production. ${ }^{(135)}$ Thus, an Asc insufficiency rather than excessive hydrogen peroxide appears to cause deleterious effects in the ER. This notion is also supported by the finding that an insufficient supply of oxygen decreases the production of hydrogen peroxide and the capacity for oxidative protein folding, which consequently leads to ER stress. ${ }^{(31)}$ Moreover, no reports have yet shown that Gulo-derived hydrogen peroxide alone induces ER damage, although excessive ROS, which is caused by a double deficiency of Prdx4 and SOD1, induces ER stress and hepatic damage in mice. ${ }^{(136)}$ Thus far, there is no robust 


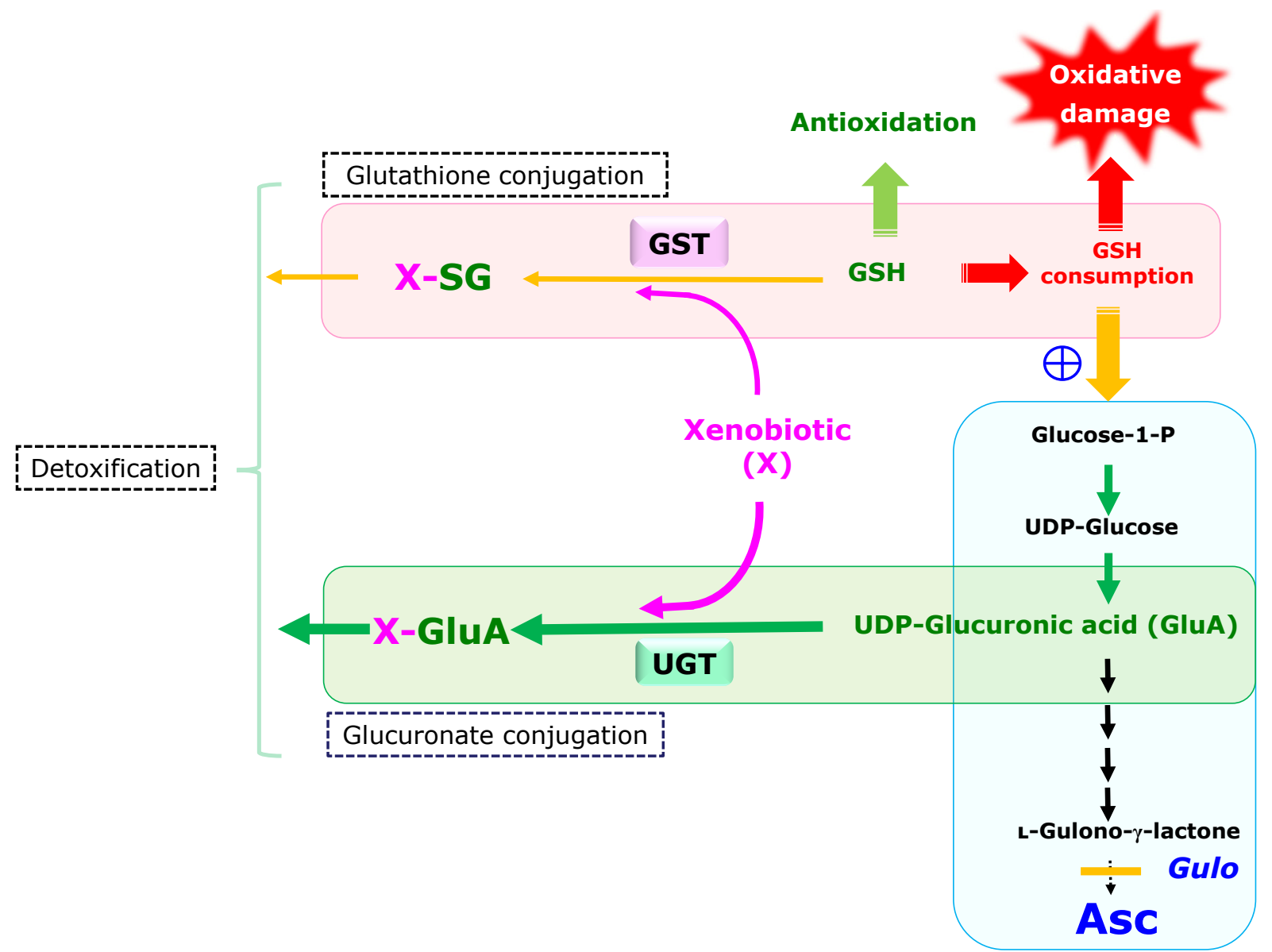

Fig. 8. Schematic representation of and crosstalk between two detoxification pathways, glutathione conjugation and glucuronate conjugation in the liver. While glutathione conjugation is catalyzed by glutathione S-transferases (GST), glucuronate conjugation is catalyzed by UGT. UGT may also catalyze the hydrolysis of UDP-glucuronate, resulting in the formation of D-glucuronate. Pathways for glucuronate conjugation and Asc synthesis share the metabolic processes up to UDP-glucuronate. Ablation of enzymes responsible for the downstream reaction causes the accumulation of intermediary compounds that include UDP-glucuronate. As a result, the glucuronate conjugation reaction is enhanced in animals that have a defect in Asc synthesis and preserve glutathione for antioxidation.

body of evidence to show that the Gulo-catalyzed reaction is a disadvantage in competent animals. Given that Gulo-deficient, Asc-incompetent animals are rather prosperous among close animal groups in the animal kingdom now, it is rational to conclude that the Asc-incompetent animals have gained an advantage in gaining prosperity in return for the loss for Asc synthesis.

\section{Enhanced Detoxification via Glucuronate Conjugation Reactions May be Used to Rationalize the Loss of Asc Synthesis}

The question still remains as to what function is gained in return for the loss of Asc synthesis and has allowed incompetent animals to become dominant during the course of evolution. Instead of focusing on the Gulo-catalyzed reaction itself, a re-examination of the upstream metabolic pathway of the Asc synthesis may provide a clue in this issue. The Asc-synthesizing pathway constitutes one of the glucose metabolism networks and the processes up to UDP-glucuronate is shared with that of glucuronate conjugation (Fig. 8). UDPglucuronate either proceeds to form L-gulonate for Asc synthesis or becomes the substrate for conjugation reactions of xenobiotics, which is performed by UDP-glucuronosyltransferase (UGT). ${ }^{(33,137)}$ Sharing the processes between the Asc synthesis and glucuronate conjugation may explain why xenobiotics stimulate Asc synthesis. UGT itself or a closely related enzyme may be responsible for the following removal of UDP from UDP-glucuronate. ${ }^{(59)}$ If UGT is identical to the enzyme, it can be regarded as the gate-keeping enzyme that dictates which pathways UDP-glucuronate takes, either glucuronate conjugation or Asc synthesis, depending on the presence or absence of xenobiotics. Upon the mutation in Gulo, however, UDPglucuronate dominantly flows to the glucuronate conjugation reaction. Consequently, a loss of the Asc synthesis would result in enhanced detoxification by means of stimulated glucuronate conjugation.

While three major conjugation reactions, glucuronate conjugation, glutathione conjugation and sulfate conjugation, are involved in detoxification of xenobiotic compounds, which are mostly hydrophobic in nature, the inhibition of glutathione synthesis by buthionine sulfoximine ${ }^{(36)}$ or glutathione consumption by stimulated glutathione conjugation ${ }^{(37)}$ reportedly increases Asc-synthesis in rodents. In the case of the xenobioticmediated glutathione consumption, the accelerated conversion of UDP-glucuronate to glucuronate is a likely cause for the elevated Asc synthesis. ${ }^{(35)}$ Hence, two detoxification pathways, glutathione conjugation and glucuronate conjugation, appear to be coordinately functioning from the standpoint of the detoxification of xenobiotics. Although, no metabolic pathways 
are directly shared between the two conjugation reactions, these pathways are in fact under common genetic regulation. Especially Nrf2 is a redox-sensitive transcriptional regulatory factor that activates antioxidative genes, including those for glutathione synthesis, and also genes for detoxification, which includes UGT. ${ }^{(138)}$ Because glutathione is also a pivotal electron donor for glutathione peroxidase reactions in antioxidation, it is conceivable that a preferential metabolic flow to glucuronate conjugation would save glutathione by providing relief for the glutathione conjugation reaction, which would lead to an augmented antioxidative capacity. Fruits are generally rich in Asc but also sometimes contain toxic compounds, notably in immature stages. ${ }^{(139)}$ Considering that ancestral primates obtain food that could contain relatively high levels of toxic compounds, individuals that have acquired strong detoxification systems, by means of glucuronate conjugation, and an antioxidation system, by means of glutathione, in return for waiving Asc synthesis would have an advantage in terms of survival.

This hypothetical adaptation may rationalize prosperity of the Asc-incompetent animals. However, is there evidence for it? Our recent studies on drug-induced hepatic injuries caused by acetaminophen (APAP) may provide a clue to this issue. ${ }^{(140-142)}$ APAP is a popular antifebrile and analgesic agent and is generally regarded as a safe medicine. Upon an overdose, however, APAP induces liver injury, which is a leading cause of drug-induced acute liver failure in several countries. ${ }^{(143)}$ Numerous studies have been carried out and the rsults show that ingested APAP is mostly excreted via either glucuronate conjugation or sulfate conjugation ${ }^{(144,145)}$ but is also partly oxidized to $N$-acetyl- $p$-benzoquinone imine (NAPQI) by cytochrome P450 (CYP) enzymes. ${ }^{(146)}$ The resulting NAPQI then undergoes glutathione conjugation, which leads to the consumption of glutathione and consequent hepatic damage. The administration of $\mathrm{N}$-acetyl cysteine, a precursor for cysteine and eventually glutathione, is the established treatment for an APAP overdose, ${ }^{(143)}$ implying the importance of glutathione maintenance in liver homeostasis.

We employed Akrla-KO mice to examine the protective effects of Asc on APAP-induced hepatic injury. While the Akrla-KO mice are more vulnerable to high doses of APAP than the WT mice, Asc supplementation renders the Akrla-KO mouse to be markedly resistant to APAP hepatotoxicity. ${ }^{(140)}$ These results alone can be simply explained by assuming that Asc exerted a hepatoprotective action via antioxidation against elevated ROS, which are elevated by the CYP reaction and the consumption of glutathione due to glutathione conjugation of NAPQI. Our most recent study, however, had some unexplainable results based on the simple antioxidant action of Asc. ${ }^{(142)}$ Under conditions of an iron load, the hepatotoxicity of APAP was comparable between WT and the Akrla-KO mice. To our surprise, however, Asc supplementation dramatically ameliorated the APAP-induced hepatic injury in the iron-loaded $A k r l a-\mathrm{KO}$ mice but had no effect on the iron-loaded WT mice. Because WT mice possesses both endogenously produced Asc and supplemented Asc, the Asc contents are actually higher in the WT mice than in the Akrla-KO mouse, and hence, the results cannot be rationalized by Asc function alone. In the meantime, our metabolomic study on the Akrla-KO mice indicated that the Akrla-KO mice had an excessive accumulation of glucuronate (41-fold in the Akrla-KO vs the WT mice) and its oxidized metabolite saccharate (102-fold in the Akrla-KO vs the WT mice) in the liver. ${ }^{(80)}$ These collective results imply that elevated oxidative stress due to an Asc deficiency in the Akrla-KO mice makes them vulnerable to APAP, but the suppression of ROS production by Asc supplementation reinforces hepatic resistance, which is accomplished by efficient detoxification via enhanced glucuronate conjugation.
It should also be noted that the levels of glucuronateconjugated APAP are actually the highest in the guinea pig among rodents that were administered APAP. ${ }^{(147)}$ Guinea pig is consistently less sensitive to APAP hepatotoxicity. These circumstantial evidences support our hypothesis on the prosperity of Asc-incompetent animals; the restriction in the carbohydrate flow to Asc synthesis enhances the detoxification of APAP by stimulated glucuronate conjugation, and at the same time, preserves glutathione, which collectively leads to the KO mouse being more resistant to APAP. Thus, the preferential carbohydrate flow to glucuronate conjugation reaction due to the loss of Asc synthesis appears to be advantageous to Gulo-deficient animals. This hypothesis explains the phenomena observed in the Ascincompetent animals and genetically modified mice but is largely based on circumstantial evidences at this moment. Thus, further experimentation will be required to verify this hypothetical mechanism for the loss of Asc synthesis.

\section{Brief Summary}

Asc is an essential micronutrient the synthesis of which primates have lost a long time ago. Because Asc exerts pivotal actions in a variety of metabolic processes and gene expression as well as functioning as an antioxidant in the body, a deficiency causes scurvy and is associated with cancer and many other diseases due to dysfunctions in physiological processes. The issue of why primates have lost synthesizing such an important molecule remains a mystery. Herein, we propose a hypothetical mechanism, which is different from the ordinary explanation; i.e., the loss of Asc synthesis due to the mutation in Gulo enhances detoxification reactions by glucuronate conjugation, which is accomplished by a preferential carbohydrate flow.

\section{Acknowledgments}

This study was supported, in part, by grants from the Japan Society for the Promotion and Science (JSPS) and the National Research Foundation (NRF) of Republic of Korea under the Japan-Korea Basic Scientific Cooperation Program.

\section{Abbreviations}

$\begin{array}{ll}\text { Akr } & \text { aldo-keto reductase } \\ \text { Akr1a } & \text { aldehyde reductase } \\ \text { Akr1b } & \text { aldose reductase } \\ \text { APAP } & \text { acetaminophen } \\ \text { Asc } & \text { ascorbate } \\ \text { CYP } & \text { cytochrome P450 } \\ \text { D-glucuronide-1-P } & \text { D-glucuronide-1-phosphate } \\ \text { DHA } & \text { dehydroascorbate } \\ \text { DNMT } & \text { DNA methyltransferase } \\ \text { ER } & \text { endoplasmic reticulum } \\ \text { Ero1 } & \text { endoplasmic reticulum oxidoreductin 1 } \\ \text { Fe }{ }^{3+} & \text { ferric iron } \\ \text { Fe } & \text { ferrous iron } \\ \text { Glc } & \text { glucose } \\ \text { glucose-6-P } & \text { glucose-6-phosphate } \\ \text { glucose-1-P } & \text { glucose-1-phosphate } \\ \text { GLUT } & \text { glucose transporter } \\ \text { G6Pase } & \text { glucose 6-phosphatase } \\ \text { Gulo } & \text { L-gulono- } \gamma \text {-lactone oxidase } \\ \text { HIF } & \text { hypoxia-inducible factor } \\ \text { H3K36 } & \text { histone H3 at lysine 36 } \\ \text { iPSC } & \text { induced pluripotent stem cell } \\ \text { JHDM } & \text { Jumonji C-domain-containing histone } \\ \text { dKG } & \text { demethylase } \\ \text { KO } & \alpha \text {-ketoglutarate } \\ & \text { knockout }\end{array}$


NAPQI

8-oxoG

PDI

$\operatorname{Prdx} 4$

Rgn

ROS

DNA methylation at the 5-position of cytosine

$N$-acetyl- $p$-benzoquinone imine

8-oxo-7,8-dihydroguanine

protein disulfide isomerase

peroxiredoxin 4

gluconolactonase

reactive oxygen species
SVCT

TET

UGT

WT

$\mathrm{Na}^{+}$-dependent vitamin $\mathrm{C}$ transporte

ten-eleven translocation

UDP-glucuronosyltransferase

wild-type

\section{Conflict of Interest}

No potential conflicts of interest were disclosed.

\section{References}

1 Szent-Györgyi A. Observations on the function of peroxidase systems and the chemistry of the adrenal cortex: description of a new carbohydrate derivative. Biochem J 1928; 22: 1387-1409.

2 Bánhegyi G, Braun L, Csala M, Puskás F, Mandl J. Ascorbate metabolism and its regulation in animals. Free Radic Biol Med 1997; 23: 793-803.

3 Drouin G, Godin JR, Pagé B. The genetics of vitamin C loss in vertebrates. Curr Genomics 2011; 12: 371-378.

4 Fenech M, Amaya I, Valpuesta V, Botella MA. Vitamin C content in fruits: biosynthesis and regulation. Front Plant Sci 2019; 9: 2006.

5 Englard S, Seifter S. The biochemical functions of ascorbic acid. Annu Rev Nutr 1986; 6: 365-406.

6 Aghajanian P, Hall S, Wongworawat MD, Mohan S. The roles and mechanisms of actions of vitamin $\mathrm{C}$ in bone: new developments. $J$ Bone Miner Res 2015; 30: 1945-1955.

7 Kaelin WG Jr, Ratcliffe PJ. Oxygen sensing by metazoans: the central role of the HIF hydroxylase pathway. Mol Cell 2008; 30: 393-402.

8 Kohli RM, Zhang Y. TET enzymes, TDG and the dynamics of DNA demethylation. Nature 2013; 502: 472-479.

9 Young JI, Züchner S, Wang G. Regulation of the epigenome by vitamin C. Annu Rev Nutr 2015; 35: 545-564.

10 Du J, Cullen JJ, Buettner GR. Ascorbic acid: chemistry, biology and the treatment of cancer. Biochim Biophys Acta 2012; 1826: 443-457.

11 Reczek CR, Chandel NS. CANCER. Revisiting vitamin C and cancer. Science 2015; 350: 1317-1318.

12 Chatterjee IB. Evolution and the biosynthesis of ascorbic acid. Science 1973; 182: $1271-1272$

13 Nishikimi M, Fukuyama R, Minoshima S, Shimizu N, Yagi K. Cloning and chromosomal mapping of the human nonfunctional gene for L-gulonogamma-lactone oxidase, the enzyme for L-ascorbic acid biosynthesis missing in man. J Biol Chem 1994; 269: 13685-13688.

14 Birney EC, Jenness R, Ayaz KM. Inability of bats to synthesise L-ascorbic acid. Nature 1976; 260: 626-628.

15 Lachapelle MY, Drouin G. Inactivation dates of the human and guinea pig vitamin C genes. Genetica 2011; 139: 199-207.

16 Traber MG, Stevens JF. Vitamins C and E: beneficial effects from a mechanistic perspective. Free Radic Biol Med 2011; 51: 1000-1013.

17 Njus D, Kelley PM, Tu YJ, Schlegel HB. Ascorbic acid: the chemistry underlying its antioxidant properties. Free Radic Biol Med 2020; 159: 37-43.

18 Lykkesfeldt J, Tveden-Nyborg P. The pharmacokinetics of vitamin C. Nutrients 2019; 11: 2412.

19 Buettner GR. The pecking order of free radicals and antioxidants: lipid peroxidation, $\alpha$-tocopherol, and ascorbate. Arch Biochem Biophys 1993; 300: 535-543.

20 Rose RC, Bode AM. Biology of free radical scavengers: an evaluation of ascorbate. FASEB J 1993; 7: 1135-1142.

21 Cobley JN, McHardy H, Morton JP, Nikolaidis MG, Close GL. Influence of vitamin $\mathrm{C}$ and vitamin $\mathrm{E}$ on redox signaling: implications for exercise adaptations. Free Radic Biol Med 2015; 84: 65-76.

22 Dixon SJ, Lemberg KM, Lamprecht MR, et al. Ferroptosis: an iron-dependent form of nonapoptotic cell death. Cell 2012; 149: 1060-1072.

23 Stockwell BR, Friedmann Angeli JP, Bayir H, et al. Ferroptosis: a regulated cell death nexus linking metabolism, redox biology, and disease. Cell 2017; 171: $273-285$.

24 Nishikimi M. Oxidation of ascorbic acid with superoxide anion generated by the xanthine-xanthine oxidase system. Biochem Biophys Res Commun 1975; 63: 463-468.

25 Homma T, Takeda Y, Nakano T, et al. Defective biosynthesis of ascorbic acid in Sod1-deficient mice 1 results in lethal damage to lung tissue. Free Radic
Biol Med 2020; S0891-5849(20)31297-1

26 Mackenzie B, Garrick MD. Iron imports. II. Iron uptake at the apical membrane in the intestine. Am J Physiol Gastrointest Liver Physiol 2005; 289: G981-G986.

27 Canavesi E, Alfieri C, Pelusi S, Valenti L. Hepcidin and HFE protein: iron metabolism as a target for the anemia of chronic kidney disease. World $J$ Nephrol 2012; 1: 166-176.

28 Lane DJ, Richardson DR. The active role of vitamin C in mammalian iron metabolism: much more than just enhanced iron absorption! Free Radic Biol Med 2014; 75: 69-83

29 Chen Q, Espey MG, Sun AY, et al. Ascorbate in pharmacologic concentrations selectively generates ascorbate radical and hydrogen peroxide in extracellular fluid in vivo. Proc Natl Acad Sci U S A 2007; 104: 87498754

30 Szarka A, Kapuy O, Lörincz T, Bánhegyi G. Vitamin C and cell death Antioxid Redox Signal 2020. DOI: 10.1089/ars.2019.7897.

31 Bánhegyi G, Mandl J, Csala M. Redox-based endoplasmic reticulum dysfunction in neurological diseases. J Neurochem 2008; 107: 20-34.

32 Linster CL, Van Schaftingen E. Vitamin C. Biosynthesis, recycling and degradation in mammals. FEBS J 2007; 274: 1-22.

33 Yang N, Sun R, Liao X, Aa J, Wang G. UDP-glucuronosyltransferases (UGTs) and their related metabolic cross-talk with internal homeostasis: a systematic review of UGT isoforms for precision medicine. Pharmacol Res 2017; 121: 169-183.

34 Gabbay KH, Bohren KM, Morello R, Bertin T, Liu J, Vogel P. Ascorbate synthesis pathway: dual role of ascorbate in bone homeostasis. $J$ Biol Chem 2010; 285: 19510-19520.

35 Linster CL, Van Schaftingen E. Rapid stimulation of free glucuronate formation by non-glucuronidable xenobiotics in isolated rat hepatocytes. $J$ Biol Chem 2003; 278: 36328-36333.

36 Mårtensson J, Meister A. Glutathione deficiency increases hepatic ascorbic acid synthesis in adult mice. Proc Natl Acad Sci U S A 1992; 89: 11566 11568.

37 Chan TS, Wilson JX, O'Brien PJ. Glycogenolysis is directed towards ascorbate synthesis by glutathione conjugation. Biochem Biophys Res Commun 2004; 317: 149-156.

38 Braun L, Csala M, Poussu A, Garzó T, Mandl J, Bánhegyi G. Glutathione depletion induces glycogenolysis dependent ascorbate synthesis in isolated murine hepatocytes. FEBS Lett 1996; 388: 173-176.

39 Fujii J, Homma T, Kobayashi S, Seo HG. Mutual interaction between oxidative stress and endoplasmic reticulum stress in the pathogenesis of diseases specifically focusing on non-alcoholic fatty liver disease. World $J$ Biol Chem 2018; 9: 1-15.

40 Tsukaguchi $\mathrm{H}$, Tokui $\mathrm{T}$, Mackenzie B, et al. A family of mammalian $\mathrm{Na}^{+}$ dependent L-ascorbic acid transporters. Nature 1999; 399: 70-75.

41 Savini I, Rossi A, Pierro C, Avigliano L, Catani MV. SVCT1 and SVCT2: key proteins for vitamin C uptake. Amino Acids 2008; 34: 347-355.

42 Vera JC, Rivas CI, Fischbarg J, Golde DW. Mammalian facilitative hexose transporters mediate the transport of dehydroascorbic acid. Nature $1993 ; \mathbf{3 6 4}$ 79-82.

43 Rumsey SC, Kwon O, Xu GW, Burant CF, Simpson I, Levine M. Glucose transporter isoforms GLUT1 and GLUT3 transport dehydroascorbic acid. $J$ Biol Chem 1997; 272: 18982-18989.

44 Rivas CI, Zúñiga FA, Salas-Burgos A, Mardones L, Ormazabal V, Vera JC. Vitamin C transporters. J Physiol Biochem 2008; 64: 357-375.

45 Sotiriou S, Gispert S, Cheng J, et al. Ascorbic-acid transporter Slc23al is essential for vitamin $\mathrm{C}$ transport into the brain and for perinatal survival. Nat Med 2002; 8: 514-517. 
46 Dhariwal KR, Hartzell WO, Levine M. Ascorbic acid and dehydroascorbic acid measurements in human plasma and serum. Am J Clin Nutr 1991; 54: $712-716$.

47 Wilson JX. Regulation of vitamin C transport. Annu Rev Nutr 2005; 25: 105 125 .

48 Hasselholt S, Tveden-Nyborg P, Lykkesfeldt J. Distribution of vitamin C is tissue specific with early saturation of the brain and adrenal glands following differential oral dose regimens in guinea pigs. Br J Nutr 2015; 113: 1539 1549 .

49 Takanaga H, Mackenzie B, Hediger MA. Sodium-dependent ascorbic acid transporter family SLC23. Pflugers Arch 2004; 447: 677-682.

50 Harrison FE, May JM. Vitamin C function in the brain: vital role of the ascorbate transporter SVCT2. Free Radic Biol Med 2009; 46: 719-730.

51 Bornstein SR, Yoshida-Hiroi M, Sotiriou S, et al. Impaired adrenal catecholamine system function in mice with deficiency of the ascorbic acid transporter (SVCT2). FASEB J 2003; 17: 1928-1930.

52 Muñoz-Montesino C, Roa FJ, Peña E, et al. Mitochondrial ascorbic acid transport is mediated by a low-affinity form of the sodium-coupled ascorbic acid transporter-2. Free Radic Biol Med 2014; 70: 241-254.

53 Corpe CP, Tu H, Eck P, et al. Vitamin C transporter Slc23al links renal reabsorption, vitamin $\mathrm{C}$ tissue accumulation, and perinatal survival in mice. $J$ Clin Invest 2010; 120: 1069-1083.

54 Corpe CP, Eck P, Wang J, Al-Hasani H, Levine M. Intestinal dehydroascorbic acid (DHA) transport mediated by the facilitative sugar transporters, GLUT2 and GLUT8. J Biol Chem 2013; 288: 9092-9101.

55 Caprile T, Salazar K, Astuya A, et al. The $\mathrm{Na}^{+}$-dependent L-ascorbic acid transporter SVCT2 expressed in brainstem cells, neurons, and neuroblastoma cells is inhibited by flavonoids. $J$ Neurochem 2009 ; 108: 563-577.

56 Agus DB, Gambhir SS, Pardridge WM, et al. Vitamin C crosses the bloodbrain barrier in the oxidized form through the glucose transporters. $J$ Clin Invest 1997; 100: 2842-2848.

57 Iyanagi T, Yamazaki I. One-electron-transfer reactions in biochemical systems. 3. One-electron reduction of quinones by microsomal flavin enzymes. Biochim Biophys Acta 1969; 172: 370-381.

58 Ito A, Hayashi S, Yoshida T. Participation of a cytochrome b5-like hemoprotein of outer mitochondrial membrane (OM cytochrome b) in NADH-semidehydroascorbic acid reductase activity of rat liver. Biochem Biophys Res Commun 1981; 101: 591-598.

59 Linster CL, Van Schaftingen E. Glucuronate, the precursor of vitamin C, is directly formed from UDP-glucuronate in liver. FEBS $J$ 2006; 273: 15161527.

60 Smirnoff N. Ascorbic acid metabolism and functions: a comparison of plants and mammals. Free Radic Biol Med 2018; 22: 116-129.

61 Szarka A, Lörincz T. The role of ascorbate in protein folding. Protoplasma 2014; 251: 489-497.

62 KC S, Cárcamo JM, Golde DW. Vitamin C enters mitochondria via facilitative glucose transporter 1 (Glut1) and confers mitochondrial protection against oxidative injury. FASEB J 2005; 19: 1657-1667.

63 Li X, Cobb CE, Hill KE, Burk RF, May JM. Mitochondrial uptake and recycling of ascorbic acid. Arch Biochem Biophys 2001; 387: 143-153.

64 Li X, Cobb CE, May JM. Mitochondrial recycling of ascorbic acid from dehydroascorbic acid: dependence on the electron transport chain. Arch Biochem Biophys 2002; 403: 103-110.

65 Mandl J, Szarka A, Bánhegyi G. Vitamin C: update on physiology and pharmacology. Br J Pharmacol 2009; 157: 1097-1110.

66 Myllyharju J, Kivirikko KI. Collagens, modifying enzymes and their mutations in humans, flies and worms. Trends Genet 2004; 20: 33-43.

67 Prockop DJ, Kivirikko KI. Collagens: molecular biology, diseases, and potentials for therapy. Annu Rev Biochem 1995; 64: 403-434.

68 Sauberlich HE. Pharmacology of vitamin C. Annu Rev Nutr 1994; 14: $371-$ 391.

69 Tomasek JJ, Gabbiani G, Hinz B, Chaponnier C, Brown RA. Myofibroblasts and mechano-regulation of connective tissue remodelling. Nat Rev Mol Cell Biol 2002; 3: 349-363.

70 Matsusaki M, Kanemura S, Kinoshita M, Lee YH, Inaba K, Okumura M. The protein disulfide isomerase family: from proteostasis to pathogenesis Biochim Biophys Acta Gen Subj 2020; 1864: 129338.

71 Zhou J, Wu Y, Wang $\mathrm{L}$, et al. The C-terminal CGHC motif of protein disulfide isomerase supports thrombosis. J Clin Invest 2015; 125: 4391-4406.

72 Saaranen MJ, Karala AR, Lappi AK, Ruddock LW. The role of dehydroascorbate in disulfide bond formation. Antioxid Redox Signal 2010; 12: $15-25$.

73 Nishikimi M, Kawai T, Yagi K. Guinea pigs possess a highly mutated gene for L-gulono-gamma-lactone oxidase, the key enzyme for L-ascorbic acid biosynthesis missing in this species. J Biol Chem 1992; 267: 21967-21972.

74 Fernandez ML. Guinea pigs as models for cholesterol and lipoprotein metabolism. J Nutr 2001; 131: 10-20.

75 Kawai T, Nishikimi M, Ozawa T, Yagi K. A missense mutation of L-gulonogamma-lactone oxidase causes the inability of scurvy-prone osteogenic disorder rats to synthesize L-ascorbic acid. J Biol Chem 1992; 267: 21973 21976.

76 Maeda N, Hagihara H, Nakata Y, Hiller S, Wilder J, Reddick R. Aortic wall damage in mice unable to synthesize ascorbic acid. Proc Natl Acad Sci U S A 2000; 97: 841-846.

$77 \mathrm{Yu} \mathrm{R}$, and Schellhorn HE. Recent applications of engineered animal antioxidant deficiency models in human nutrition and chronic disease. $J$ Nutr 2013; 143: 1-11.

78 Kondo Y, Inai Y, Sato Y, et al. Senescence marker protein 30 functions as gluconolactonase in L-ascorbic acid biosynthesis, and its knockout mice are prone to scurvy. Proc Natl Acad Sci U S A 2006; 103: 5723-5728.

79 Aizawa S, Senda M, Harada A, et al. Structural basis of the $\gamma$-lactone-ring formation in ascorbic acid biosynthesis by the senescence marker protein-30/ gluconolactonase. PLoS One 2013; 8: e53706.

80 Takahashi M, Miyata S, Fujii J, et al. In vivo role of aldehyde reductase. Biochim Biophys Acta 2012; 1820: 1787-1796.

81 Nishida H, Kurahashi T, Saito Y, et al. Kidney fibrosis is independent of the amount of ascorbic acid in mice with unilateral ureteral obstruction. Free Radic Res 2014; 48: 1115-1124.

82 Fujii J, Homma T, Kobayashi S. Chapter 11: ascorbic acid as a multifunctional nutrient in mammals; our understanding based on studies using genetically modified mice. In: Parsons E, ed. Ascorbic Acid: Properties, Synthesis and Applications, Hauppauge: Nova Science Publishers Inc, 2016; 239-265.

83 Spite M, Baba SP, Ahmed Y, et al. Substrate specificity and catalytic efficiency of aldo-keto reductases with phospholipid aldehydes. Biochem $J$ 2007; 405: 95-105.

84 Zhou HL, Zhang R, Anand $\mathrm{P}$, et al. Author correction: metabolic reprogramming by the $S$-nitroso-CoA reductase system protects against kidney injury. Nature 2019; 570: E23.

85 Takahashi M, Homma T, Yamada KI, Miyata S, Nakajima O, Fujii J. Genetic ablation of aldehyde reductase (Akrla) augments exercise endurance in mice via activation of the PGC-1 $\alpha$-involved pathway. Life Sci 2020; 249: 117501.

86 Sato Y, Kajiyama S, Amano A, et al. Hydrogen-rich pure water prevents superoxide formation in brain slices of vitamin C-depleted SMP30/GNL knockout mice. Biochem Biophys Res Commun 2008; 375: 346-350.

87 Koike K, Kondo Y, Sekiya M, et al. Complete lack of vitamin C intake generates pulmonary emphysema in senescence marker protein-30 knockout mice. Am J Physiol Lung Cell Mol Physiol 2010; 298: L784-L792.

88 Kondo Y, Masutomi H, Noda Y, et al. Senescence marker protein-30/ superoxide dismutase 1 double knockout mice exhibit increased oxidative stress and hepatic steatosis. FEBS Open Bio 2014; 4: 522-532.

89 Parsons KK, Maeda N, Yamauchi M, Banes AJ, Koller BH. Ascorbic acidindependent synthesis of collagen in mice. Am J Physiol Endocrinol Metab 2006; 290: E1131-E1139.

90 Arai KY, Sato Y, Kondo Y, et al. Effects of vitamin C deficiency on the skin of the senescence marker protein-30 (SMP30) knockout mouse. Biochem Biophys Res Commun 2009; 385: 478-483.

91 Amano A, Tsunoda M, Aigaki T, Maruyama N, Ishigami A. Effect of ascorbic acid deficiency on catecholamine synthesis in adrenal glands of SMP30/GNL knockout mice. Eur J Nutr 2014; 53: 177-185.

92 Homma T, Akihara R, Okano S, et al. Heightened aggressive behavior in mice deficient in aldo-keto reductase 1a (Akr1a). Behav Brain Res 2017; 319 219-224.

93 Kurihara K, Homma T, Kobayashi S, et al. Ascorbic acid insufficiency impairs spatial memory formation in juvenile AKR1A-knockout mice. J Clin Biochem Nutr 2019; 65: 209-216.

94 Kim H, Bae S, Kim Y, et al. Vitamin C prevents stress-induced damage on the heart caused by the death of cardiomyocytes, through down-regulation of the excessive production of catecholamine, TNF- $\alpha$, and ROS production in Gulo(-/-) $)^{\text {Vit C-Insufficient }}$ mice. Free Radic Biol Med 2013; 65: 573-583. 
95 Seifermann M, Epe B. Oxidatively generated base modifications in DNA: not only carcinogenic risk factor but also regulatory mark? Free Radic Biol Med 2017; 107: 258-265.

96 Sram RJ, Binkova B, Rossner P Jr. Vitamin C for DNA damage prevention. Mutat Res 2012; 733: 39-49.

97 Chen Z, Zhang Y. Role of mammalian DNA methyltransferases in development. Annu Rev Biochem 2020; 89: 135-158.

98 Varier RA, Timmers HT. Histone lysine methylation and demethylation pathways in cancer. Biochim Biophys Acta 2011; 1815: 75-89.

99 Rea S, Eisenhaber F, O'Carroll D, et al. Regulation of chromatin structure by site-specific histone H3 methyltransferases. Nature 2000; 406: 593-599.

100 Esteban MA, Wang T, Qin B, et al. Vitamin C enhances the generation of mouse and human induced pluripotent stem cells. Cell Stem Cell 2010; 6: 71-79.

101 Gillberg L, Ørskov AD, Liu M, Harsløf LBS, Jones PA, Grønbæk K. Vitamin $\mathrm{C}$ - a new player in regulation of the cancer epigenome. Semin Cancer Biol 2018; 51: 59-67.

102 Cimmino L, Neel BG, Aifantis I. Vitamin C in stem cell reprogramming and cancer. Trends Cell Biol 2018; 28: 698-708.

103 Tahiliani M, Koh KP, Shen Y, et al. Conversion of 5-methylcytosine to 5hydroxymethylcytosine in mammalian DNA by MLL partner TET1. Science 2009; 324: 930-935.

$104 \mathrm{He}$ YF, Li BZ, Li Z, et al. Tet-mediated formation of 5-carboxylcytosine and its excision by TDG in mammalian DNA. Science 2011; 333: 1303-1307.

105 Blaschke K, Ebata KT, Karimi MM, et al. Vitamin C induces Tet-dependent DNA demethylation and a blastocyst-like state in ES cells. Nature 2013; 500: $222-226$.

106 Tsukada Y, Fang J, Erdjument-Bromage H, et al. Histone demethylation by a family of JmjC domain-containing proteins. Nature 2006; 439: 811-816.

107 Wang T, Chen K, Zeng X, et al. The histone demethylases Jhdmla/1b enhance somatic cell reprogramming in a vitamin-C-dependent manner. Cell Stem Cell 2011; 9: 575-587.

108 Monfort A, Wutz A. Breathing-in epigenetic change with vitamin C. EMBO Rep 2013; 14: 337-346.

109 Cameron E, Pauling L. Supplemental ascorbate in the supportive treatment of cancer: prolongation of survival times in terminal human cancer. Proc Natl Acad Sci U S A 1976; 73: 3685-3689.

110 Cameron E, Pauling L. Supplemental ascorbate in the supportive treatment of cancer: reevaluation of prolongation of survival times in terminal human cancer. Proc Natl Acad Sci US A 1978; 75: 4538-4542.

111 Creagan ET, Moertel CG, O'Fallon JR, et al. Failure of high-dose vitamin C (ascorbic acid) therapy to benefit patients with advanced cancer. A controlled trial. N Engl J Med 1979; 301: 687-690.

112 Moertel CG, Fleming TR, Creagan ET, Rubin J, O'Connell MJ, Ames MM. High-dose vitamin $\mathrm{C}$ versus placebo in the treatment of patients with advanced cancer who have had no prior chemotherapy. A randomized doubleblind comparison. $N$ Engl J Med 1985; 312: 137-141.

113 Toyokuni S, Ito F, Yamashita K, Okazaki Y, Akatsuka S. Iron and thiol redox signaling in cancer: an exquisite balance to escape ferroptosis. Free Radic Biol Med 2017; 108: 610-626.

114 Cha J, Roomi MW, Ivanov V, Kalinovsky T, Niedzwiecki A, Rath M. Ascorbate depletion increases growth and metastasis of melanoma cells in vitamin C deficient mice. Exp Oncol 2011; 33: 226-230.

115 Kasprzak KS, Diwan BA, Kaczmarek MZ, Logsdon DL, Fivash MJ, Salnikow K. Effects of ascorbic acid on carcinogenicity and acute toxicity of nickel subsulfide, and on tumor transplants growth in gulonolactone oxidase knock-out mice and wild-type C57BL mice. Toxicol Appl Pharmacol 2011; 257: 32-37.

116 Campbell EJ, Vissers MC, Bozonet S, Dyer A, Robinson BA, Dachs GU. Restoring physiological levels of ascorbate slows tumor growth and moderates HIF-1 pathway activity in Gulo(-/-) mice. Cancer Med 2015; 4: 303-314.

117 Son YS, Ullah HMA, Elfadl AK, et al. Preventive effects of vitamin C on diethylnitrosamine-induced hepatotoxicity in Smp30 knockout mice. In Vivo 2018; 32: 93-99.

118 Ishii N, Homma T, Guo X, Yamada KI, Yamada S, Fujii J. Ascorbic acid prevents $N$-nitrosodiethylamine-induced hepatic injury and hepatocarcinogenesis in Akrla-knockout mice. Toxicol Lett 2020; 333: 192 201.

119 Semenza GL. Hypoxia-inducible factor 1 and cardiovascular disease. Annu
Rev Physiol 2014; 76: 39-56.

120 Pawlowska E, Szczepanska J, Blasiak J. Pro- and antioxidant effects of vitamin $\mathrm{C}$ in cancer in correspondence to its dietary and pharmacological concentrations. Oxid Med Cell Longev 2019; 2019: 7286737.

121 Shenoy N, Creagan E, Witzig T, Levine M. Ascorbic acid in cancer treatment: let the phoenix fly. Cancer Cell 2018; 34: 700-706.

122 Vissers MCM, Das AB. Potential mechanisms of action for vitamin C in cancer: reviewing the evidence. Front Physiol 2018; 9: 809.

123 Graumlich JF, Ludden TM, Conry-Cantilena C, Cantilena LR Jr, Wang Y, Levine M. Pharmacokinetic model of ascorbic acid in healthy male volunteers during depletion and repletion. Pharm Res 1997; 14: 1133-1139.

124 Drisko JA, Chapman J, Hunter VJ. The use of antioxidants with first-line chemotherapy in two cases of ovarian cancer. J Am Coll Nutr 2003; 22: 118 123.

125 Riordan HD, Casciari JJ, González MJ, et al. A pilot clinical study of continuous intravenous ascorbate in terminal cancer patients. $P R$ Health Sci $J$ 2005; 24: 269-276.

126 Schoenfeld JD, Sibenaller ZA, Mapuskar KA, et al. $\mathrm{O}_{2}{ }^{--}$and $\mathrm{H}_{2} \mathrm{O}_{2}$-mediated disruption of $\mathrm{Fe}$ metabolism causes the differential susceptibility of NSCLC and GBM cancer cells to pharmacological ascorbate. Cancer Cell 2017; 31: 487-500.

127 Badu-Boateng C, Naftalin RJ. Ascorbate and ferritin interactions: consequences for iron release in vitro and in vivo and implications for inflammation. Free Radic Biol Med 2019; 133: 75-87.

128 Yun J, Mullarky E, Lu C, et al. Vitamin C selectively kills KRAS and BRAF mutant colorectal cancer cells by targeting GAPDH. Science 2015; 350: 1391-1396.

129 Di Tano M, Raucci F, Vernieri C, et al. Synergistic effect of fastingmimicking diet and vitamin $\mathrm{C}$ against KRAS mutated cancers. Nat Commun 2020; 11: 2332 .

130 Martin RE, Cao Z, Bulleid NJ. Regulating the level of intracellular hydrogen peroxide: the role of peroxiredoxin IV. Biochem Soc Trans 2014; 42: 42-46.

131 Enyedi B, Várnai P, Geiszt M. Redox state of the endoplasmic reticulum is controlled by Ero1L-alpha and intraluminal calcium. Antioxid Redox Signal 2010; 13: 721-729.

132 Araki K, Inaba K. Structure, mechanism, and evolution of Erol family enzymes. Antioxid Redox Signal 2012; 16: 790-799.

133 Fujii J, Ikeda Y, Kurahashi T, Homma T. Physiological and pathological views of peroxiredoxin 4. Free Radic Biol Med 2015; 83: 373-379.

134 Iuchi Y, Okada F, Tsunoda S, et al. Peroxiredoxin 4 knockout results in elevated spermatogenic cell death via oxidative stress. Biochem $J$ 2009; 419: $149-158$.

135 Zito E, Hansen HG, Yeo GS, Fujii J, Ron D. Endoplasmic reticulum thiol oxidase deficiency leads to ascorbic acid depletion and noncanonical scurvy in mice. Mol Cell 2012; 48: 39-51.

136 Homma T, Kurahashi T, Lee J, Nabeshima A, Yamada S, Fujii J. Double knockout of peroxiredoxin $4(\operatorname{Prdx} 4)$ and superoxide dismutase 1 (Sod1) in mice results in severe liver failure. Oxid Med Cell Longev 2018; 2018: 2812904.

137 Oda S, Fukami T, Yokoi T, Nakajima M. A comprehensive review of UDPglucuronosyltransferase and esterases for drug development. Drug Metab Pharmacokinet 2015; 30: 30-51.

138 Yamamoto M, Kensler TW, Motohashi H. The KEAP1-NRF2 system: a thiolbased sensor-effector apparatus for maintaining redox homeostasis. Physiol Rev 2018; 98: 1169-1203.

139 Rameshrad M, Razavi BM, Hosseinzadeh H. Protective effects of green tea and its main constituents against natural and chemical toxins: a comprehensive review. Food Chem Toxicol 2017; 100: 115-137.

140 Kurahashi $\mathrm{T}$, Lee J, Nabeshima A, et al. Ascorbic acid prevents acetaminophen-induced hepatotoxicity in mice by ameliorating glutathione recovery and autophagy. Arch Biochem Biophys 2016; 604: 36-46.

141 Kang ES, Lee J, Homma T, et al. xCT deficiency aggravates acetaminopheninduced hepatotoxicity under inhibition of the transsulfuration pathway. Free Radic Res 2017; 51: 80-90.

142 Moon G, Kobayashi S, Naing YA, Yamada K, Yamakawa M, Fujii J. Iron loading exerts synergistic action via a different mechanistic pathway from that for acetaminophen-induced hepatic injury in mice. Free Radic Res 2020 ; 54: 606-619.

143 Reuben A, Tillman H, Fontana RJ, et al. Outcomes in adults with acute liver failure between 1998 and 2013: an observational cohort study. Ann Intern 
Med 2016; 164: 724-732.

144 Cummings AJ, King ML, Martin BK. A kinetic study of drug elimination: the excretion of paracetamol and its metabolites in man. $\mathrm{Br} J$ Pharmacol Chemother 1967; 29: 150-157.

145 Court MH, Duan SX, von Moltke LL, et al. Interindividual variability in acetaminophen glucuronidation by human liver microsomes: identification of relevant acetaminophen UDP-glucuronosyltransferase isoforms. $J$ Pharmacol Exp Ther 2001; 299: 998-1006.

146 Lee SS, Buters JT, Pineau T, Fernandez-Salguero P, Gonzalez FJ. Role of CYP2E1 in the hepatotoxicity of acetaminophen. $J$ Biol Chem 1996; 271:
12063-12067.

147 Gregus Z, Madhu C, Klaassen CD. Species variation in toxication and detoxication of acetaminophen in vivo: a comparative study of biliary and urinary excretion of acetaminophen metabolites. J Pharmacol Exp Ther 1988; 244: 91-99. This is an open access article distributed under the terms of the
Creative Commons Attribution-NonCommercial-NoDerivatives License (http://creativecommons.org/licenses/by-nc-nd/4.0/). 